\title{
Probing the effect of radiation damage on the structure of rare-earth phosphates
}

\author{
Mohamed Ruwaid Rafiuddin and Andrew P. Grosvenor*
}

Department of Chemistry, University of Saskatchewan, Saskatoon, SK, Canada, S7N 5C9

* Author to whom correspondence should be addressed

E-mail: andrew.grosvenor@usask.ca

Phone: (306) 966-4660

Fax: (306) 966-4730 


\begin{abstract}
Synthetic analogues of naturally occurring monazite $\left(\mathrm{REPO}_{4} ; \mathrm{RE}=\mathrm{La}\right.$ to $\left.\mathrm{Gd}\right)$ and xenotime $\left(\mathrm{RE}^{\prime} \mathrm{PO}_{4} ; \mathrm{RE}\right.$ ' $=\mathrm{Tb}$ to $\mathrm{Lu}$ and $\left.\mathrm{Y}\right)$ minerals have been identified as potential wasteforms for nuclear waste. High energy ion-implantation of crystalline materials simulates radiation-induced structural damage and allows for the radiation resistance of a crystal structure to be probed. The structural stability of $\mathrm{Au}^{-}$ion-implanted $\mathrm{La}_{1-\mathrm{x}} \mathrm{Yb}_{\mathrm{x}} \mathrm{PO}_{4}$ materials was investigated using micro-Xray diffraction $(\mu-\mathrm{XRD})$ and glancing angle X-ray absorption near-edge spectroscopy (GAXANES $)$ in this study. The long- and short- range order of $\mathrm{La}_{1-\mathrm{x}} \mathrm{Yb}_{\mathrm{x}} \mathrm{PO}_{4}(\mathrm{x}=0,0.3,0.7,1.0)$ is affected by ion-implantation and, thus, the materials are prone to structural damage. The structures of some members of the $\mathrm{La}_{1-\mathrm{x}} \mathrm{Yb}_{\mathrm{x}} \mathrm{PO}_{4}$ series $(\mathrm{x}=0.7$ and 1.0) were observed to partially recover after being implanted with $\mathrm{Au}^{-}$ions to a high dose. The structures of all members of the $\mathrm{La}_{1-\mathrm{x}} \mathrm{Yb}_{\mathrm{x}} \mathrm{PO}_{4}$ series were observed to recover from damage resulting from ionimplantation after annealing the materials at temperatures $\geq 300^{\circ} \mathrm{C}$.
\end{abstract}

Keywords: Monazite; xenotime; radiation-induced structural damage; wasteform; GA-XANES; $\mu-X R D$ 


\section{Introduction}

Single- and multi-phase crystalline ceramics that are resistant to radiation damage have been proposed as candidate materials for encapsulating radioactive waste [1-4]. Monazite and xenotime are naturally occurring rare-earth phosphate minerals that are being considered as hostmatrices for nuclear waste because of the ability of these structures to contain actinide elements [5-7]. These mineral phases have been observed as solid solutions with one another in igneous and metamorphic rocks [8]. Both the monazite- and xenotime-type rare-earth phosphates possess the same general formula $\mathrm{REPO}_{4}$, where $\mathrm{RE}$ represents the rare-earth element. The rare-earth site in monazite and xenotime are occupied by lighter ( $\mathrm{La}$ to $\mathrm{Gd}$ ) or heavier rare-earths ( $\mathrm{Lu}$ to $\mathrm{Yb}$ and Y), respectively [9]. Materials adopting the monazite-type structure crystallize in a monoclinic (space group - $\left.P 2{ }_{1} / n\right)$ unit cell while materials adopting the xenotime-type structure $\left(\mathrm{YPO}_{4}\right)$ crystallize in a tetragonal (space group - I4 $4_{1} /$ amd) unit cell (Figure 1) [9-11]. In monazite (e.g., $\left.\mathrm{CePO}_{4}\right)$, the $\mathrm{RE}^{3+}$ ion is bonded to nine oxygen atoms $\left(\mathrm{REO}_{9}\right)$ in a non-symmetrical fashion (point group - $\mathrm{C}_{\mathrm{s}}$ ) whereas in xenotime (e.g., $\mathrm{YPO}_{4}$ ), the $\mathrm{RE}^{3+}$ ion is coordinated to eight oxygen atoms $\left(\mathrm{REO}_{8}\right)$ in a symmetrical fashion (point group - $\mathrm{D}_{2 \mathrm{~d}}$ ) [9-13]. A more detailed description of the monazite and xenotime crystal structures can be found elsewhere [9-13].

An actinide element incorporated in a crystalline ceramic can undergo a radioactive decay process during which it may (depending upon the decay process) transform into a new radionuclide by releasing a high-energy $\alpha$-particle [14]. Because of this decay, the crystalline host matrix could experience structural damage either from the recoil energy associated with the daughter product radionuclide and/or from the highly energetic $\alpha$-particle [14]. Therefore, an issue surrounding actinide containing crystalline ceramics is the tendency of these materials to undergo a radiation-induced crystalline to amorphous transition in a process called metamiction 
$[4,14,15]$. This process can have an adverse effect on the chemical durability of the wasteform (i.e., an increase in the leach rate of the sequestered elements) $[5,16]$. This transition can also be accompanied by a swelling of the wasteform [4,5,14-19]. Naturally occurring mineral samples of monazite and xenotime are known to contain significant amounts of $\mathrm{UO}_{2}$ and $\mathrm{ThO}_{2}[6,20]$. Despite the presence of radioactive $\mathrm{U}$ and $\mathrm{Th}$, the mineral monazite, in particular, has been observed to maintain its structural integrity over a geological timescale and it is because of this resistance to radiation-induced structural damage that monazite-type ceramics have been proposed as a solid-state repository for actinide elements $[1,21,22]$. On the other hand, the structural stability of the xenotime structure is not well-documented in the literature with the exception of a few studies $[6,16,23]$.

Numerous investigations on the structural stability of natural as well as synthetic monazite samples are reported in the literature [6,24-27]. The structural stability of synthetic monazite samples have been studied either by doping monazite ceramics with actinides (internal irradiation) or by simulating the long-term actinide storage by implantation of the material using high-energy ion beams (external irradiation) [6,24-27]. Since many actinides have a very long half-life, the structural stability of a crystalline wasteform is most often determined by ionimplantation [27]. Heavy ions (such as $\mathrm{Au}^{-}, \mathrm{Kr}^{+}$, and $\mathrm{Ar}^{+}$) are generally used to simulate the effects of the daughter product on the crystal structure of a proposed wasteform $[6,21,26,27,31]$. In an early study on the radiation resistance of the monazite structure, Karioris et al. showed the monazite structure to be unstable towards heavy ion-implantation; however, they also showed that the damaged monazite structure could be converted back to its original crystalline state after annealing the irradiated material to $\sim 296^{\circ} \mathrm{C}$ for 20 hours [28]. In another study, Meldrum et al. experimentally determined the critical amorphization temperature $\left(\mathrm{T}_{\mathrm{c}} ;\right.$ i.e., the temperature above 
which the material does not undergo metamiction) of a variety of ion-implanted ternary monazite- and xenotime-type orthophosphates and found the monazite structure to have a lower $\mathrm{T}_{\mathrm{c}}$ than the xenotime structure [6]. This observation could suggest that the monazite structure is more resistant to radiation damage than the xenotime structure [6]. In a more recent study, Deschanels et al. performed thermal annealing experiments on $\mathrm{Au}^{-}$ion-implanted monazite ceramics and studied them using transmission electron microscopy (TEM) [27]. It was shown in this study that complete recrystallization of metamict monazite occurred after annealing the material to $300^{\circ} \mathrm{C}$ for 1 hour [27]. In addition to observing annealing-induced recrystallization, Deschanels et al. also observed the recrystallization of amorphous regions in damaged monazite samples under the influence of an electron beam [27]. A theoretical study of the radiation resistance of xenotime $\left(\mathrm{YPO}_{4}\right)$ by Urusov et al. shed light on the ability of recoil atoms to bring about a cascade of atomic displacements in this structure [23]. Immediately after the creation of a cascade of atomic displacements, some of the displaced atoms returned to their original crystallographic positions which led to the partial recovery of the xenotime structure [23].

The design of new crystalline wasteforms that are resistant to radiation damage requires a detailed understanding of the electronic structure of a material before and after exposure to radiation. In this context, the electronic structure can be studied using X-ray absorption nearedge spectroscopy (XANES) as it provides information on the local coordination environment, oxidation state, and bonding environment of the absorbing atom [32]. In a previous study, the authors of the present study investigated the electronic structure of three series of monazitexenotime solid solutions ( $\mathrm{La}_{1-\mathrm{x}} \mathrm{Yb}_{\mathrm{x}} \mathrm{PO}_{4}, \mathrm{La}_{1-\mathrm{x}} \mathrm{Y}_{\mathrm{x}} \mathrm{PO}_{4}$, and $\left.\mathrm{Sm}_{1-\mathrm{x}} \mathrm{Ho}_{\mathrm{x}} \mathrm{PO}_{4}\right)$ using XANES [33]. It was shown in this study that the P K-edge XANES spectra provide a spectroscopic fingerprint 
for the monazite and xenotime structures because of the distinct change in spectral lineshape and absorption energy observed between the two structures [33].

The effect of $\mathrm{Au}^{-}$ion-implantation on the structure of $\mathrm{La}_{1-\mathrm{x}} \mathrm{Yb}_{\mathrm{x}} \mathrm{PO}_{4}$ is discussed in the current study. The La and $\mathrm{Yb}$ end-members crystallize in either the monoclinic monazite $(\mathrm{x}=0)$ or tetragonal xenotime $(x=1)$ structure, respectively. At all other values of ' $x$ ', a mixture of both monazite and xenotime phases exist, which allows for an investigation of co-mineralized samples [33]. The $\mathrm{Au}^{-}$ions used in the study were implanted in the near-surface region of these materials which required the use of surface-sensitive glancing angle XANES (GA-XANES) and micro X-ray diffraction ( $\mu$-XRD) to investigate the effect of ion-implantation on the local and long range structure of these materials [34]. The extent of structural damage in $\mathrm{La}_{1-\mathrm{x}} \mathrm{Yb}_{\mathrm{x}} \mathrm{PO}_{4}$ was studied as a function of depth by varying the X-ray angle of incidence during the GA-XANES experiments. This study has allowed for a detailed comparison of the response of the monazite and xenotime structure to ion-implantation. Although GA-XANES has been utilized in determining the structural stability of metal oxides (zirconolites and pyrochlores), no studies exist in the literature on the use of this technique to the investigation of the structural stability of rare-earth phosphates [31,35].

\section{Experimental Section}

\subsection{Synthesis and Powder XRD}

Rare-earth phosphates having the composition $\mathrm{La}_{1-\mathrm{x}} \mathrm{Yb}_{\mathrm{x}} \mathrm{PO}_{4}(\mathrm{x}=0.0,0.3,0.7,1.0)$ were synthesized by conventional solid state methods. Stoichiometric amounts of $\mathrm{La}_{2} \mathrm{O}_{3}$ (Alfa Aesar; 99.99\%), $\mathrm{Yb}_{2} \mathrm{O}_{3}$ (Alfa Aesar; 99.99\%), and $\mathrm{NH}_{4} \mathrm{H}_{2} \mathrm{PO}_{4}$ (Alfa Aesar; 99.995\%) were ground and mixed using a mortar and pestle before placing the mixture in an alumina crucible. The crucible 
containing the mixture was initially heated to $900{ }^{\circ} \mathrm{C}$ in air for 1 day to promote the decomposition of $\mathrm{NH}_{4} \mathrm{H}_{2} \mathrm{PO}_{4}$ followed by quench cooling in air. The resulting mixture was ground, pressed into a pellet at a pressure of $6 \mathrm{MPa}$, and fired at $1100-1200{ }^{\circ} \mathrm{C}$ in air for 9 days before being quench cooled in air. The synthesis of $\mathrm{La}_{1-\mathrm{x}} \mathrm{Yb}_{\mathrm{x}} \mathrm{PO}_{4}$ materials was carried out at $1100^{\circ} \mathrm{C}$ for the $\mathrm{x}=0$ material and $1200^{\circ} \mathrm{C}$ for all other materials $(\mathrm{x}=0.3,0.7,1.0)$. All samples were ground and pelleted every 3 days of heating to ensure the homogeneity of the samples. The hardness of the materials was improved by pressing the materials into pellets at $8 \mathrm{MPa}$ followed by annealing at $1100-1200{ }^{\circ} \mathrm{C}$ in air for 3-4 days prior to $\mathrm{Au}^{-}$ion implantation. The phase purity of the synthesized materials was determined by powder X-ray diffraction using a PANalytical Empyrean system and a $\mathrm{Cu} \mathrm{K} \alpha_{1,2}$ X-ray source. The powder XRD patterns of the $\mathrm{La}_{1-\mathrm{x}} \mathrm{Yb}_{\mathrm{x}} \mathrm{PO}_{4}$ compounds were collected at room temperature in the $2 \theta$ range of $10-80^{\circ}$ using a step size of $0.02^{\circ}$. The lattice parameters and the percent composition of these materials were determined using the HighScore Plus software program [37]. The sample plate was continuously rotated to avoid preferential orientation effects during data collection.

\subsection{Ion Beam Implantation}

Ion beam implantation experiments were carried out using the $1.7 \mathrm{MeV}$ high-current Tandetron accelerator located at Interface Science Western (ISW), the University of Western Ontario. $\mathrm{La}_{1-\mathrm{x}} \mathrm{Yb}_{\mathrm{x}} \mathrm{PO}_{4}(\mathrm{x}=0.0,0.3,0.7,1.0)$ pellets were implanted with $2 \mathrm{MeV} \mathrm{Au}^{-}$ions to a dose of $1 \times 10^{14}, 5 \times 10^{14}$, or $1 \times 10^{15}$ ions $/ \mathrm{cm}^{2}$ in order to simulate structural damage resulting from the decay of radioactive elements. The surface of the pellets was aligned normal to the incident $\mathrm{Au}^{-}$ion beam for ion implantation. The ion-implanted $\mathrm{La}_{1-\mathrm{x}} \mathrm{Yb}_{\mathrm{x}} \mathrm{PO}_{4}$ samples were also annealed at temperatures lower than the synthesis temperature to examine if the structure of the material 
was able to recover. The annealing experiments were performed by heating the ion-implanted $\mathrm{La}_{1-\mathrm{x}} \mathrm{Yb}_{\mathrm{x}} \mathrm{PO}_{4}$ materials to $300^{\circ} \mathrm{C}$ or $900^{\circ} \mathrm{C}$ in air for 3 days.

The ion beam implantation depth profiles of $\mathrm{La}_{1-\mathrm{x}} \mathrm{Yb}_{\mathbf{x}} \mathrm{PO}_{4}$, and the corresponding number of vacancies generated per nanometer by the $\mathrm{Au}^{-}$ions, were calculated using the Stopping and Range of Ions in Matter (SRIM-2013) software package [38]. The calculations were performed using a total of $5000 \mathrm{Au}^{-}$ions and the displacement energies of the target atoms $\mathrm{La}, \mathrm{Yb}$, and $\mathrm{P}$ were assumed to be $25 \mathrm{eV}$ and the displacement energy of $\mathrm{O}$ was assumed to be $28 \mathrm{eV}$ [38]. The real values of the displacement energies for the target atoms ( $\mathrm{La}, \mathrm{Yb}, \mathrm{P}$, and $\mathrm{O}$ ) are unknown so the default displacement energy values from the SRIM software program were used during the calculations [30,38]. The densities of $\mathrm{La}_{1-\mathrm{x}} \mathrm{Yb}_{\mathrm{x}} \mathrm{PO}_{4}(\mathrm{x}=0.0,0.3,0.7,1.0)$ that were used in these calculations were: $4.93 \mathrm{~g} / \mathrm{cm}^{3}, 5.87 \mathrm{~g} / \mathrm{cm}^{3}, 6.20 \mathrm{~g} / \mathrm{cm}^{3}$, and $6.45 \mathrm{~g} / \mathrm{cm}^{3}$, respectively [39,40]. These calculations have shown that the ions implant to a depth ranging between 50 and $450 \mathrm{~nm}$ with the maximum number of implanted $\mathrm{Au}^{-}$ions being observed at $\sim 275 \mathrm{~nm}$ (see Figure 2 and Figure S1 in supporting information). The maximum number of vacancies produced in the materials because of implantation by high-energy $\mathrm{Au}^{-}$ions is observed at a depth of $\sim 200 \mathrm{~nm}$ below the surface (see Figure 2 and Figure $\mathrm{S} 1$ in supporting information).

The electronic and nuclear stopping powers of $\mathrm{La}_{1-\mathrm{x}} \mathrm{Yb}_{\mathbf{x}} \mathrm{PO}_{4}$ materials were also calculated using the SRIM-2013 software package and are presented in Table 1 [38]. A higher electronic to nuclear stopping power (ENSP) ratio generally indicates a lower defect accumulation because of the greater delocalization of point defects [6,41]. In $\mathrm{La}_{1-\mathrm{x}} \mathrm{Yb}_{\mathrm{x}} \mathrm{PO}_{4}$, the La end-member $(\mathrm{x}=0)$ adopting the monazite structure has a higher ENSP ratio than the $\mathrm{Yb}$ end-member $(\mathrm{x}=1)$ adopting the xenotime structure (Table 1). This would indicate that the defect accumulation in the monazite structure is lower in comparison to the xenotime structure $[6,41]$. 


\subsection{Micro-X-ray diffraction ( $\mu$-XRD)}

Micro-XRD was performed on the ion-implanted $\mathrm{La}_{1-\mathrm{x}} \mathrm{Yb}_{\mathrm{x}} \mathrm{PO}_{4}(\mathrm{x}=0,0.3,0.7,1)$ materials using a PANalytical Empyrean system and a $\mathrm{Cu} \mathrm{K} \alpha_{1,2}$ source to understand the stability of these materials on the long-range scale. The size of the X-ray beam was reduced to $200 \mu \mathrm{m}$ using a monocapillary collimator in order to selectively collect the diffraction patterns from the surface of the ion-implanted pellets. It should be noted that the collected diffractograms provide information on both the surface and bulk regions of the ion-implanted materials. The pellets were mounted on a goniometer that allows for translation of the sample in $\mathrm{x}, \mathrm{y}$, and $\mathrm{z}$ directions. The goniometer head allows for tilting the samples. Sample alignment was performed with the help of a microscope to position the X-ray beam on the surface of the pellets. The $\mu$-XRD patterns were collected at room temperature in the $2 \theta$ range of $10^{\circ}-60^{\circ}$ using a step size of $0.02^{\circ}$ and analyzed using the HighScore Plus software package [37]. It should be noted that this experimental set-up did not permit spinning of the sample during data collection and, therefore, preferential orientation effects could be observed in the $\mu$-XRD patterns.

\subsection{XANES}

\subsubsection{P K- and La L3-edge GA-XANES}

P K- and $\mathrm{La} \mathrm{L}_{3}$-edge GA-XANES spectra from ion-implanted $\mathrm{La}_{1-\mathrm{x}} \mathrm{Yb}_{\mathrm{x}} \mathrm{PO}_{4}$ were collected using the Soft X-ray Microcharacterization Beamline (SXRMB; 06B1-1) located at the Canadian Light Source (CLS) [42]. The ion-implanted pellets were mounted on carbon tape before being placed in the vacuum chamber. The GA-XANES spectra were collected from the surface of the pellets by allowing the X-rays to hit the sample surface at an angle greater than the critical angle for total external reflection [43]. Since the attenuation depths of X-rays depend strongly on the 
angle between the X-ray beam and the sample surface, XANES spectra can be collected from different regions of the material by tuning the X-ray angle of incidence. The X-ray attenuation depths, and the corresponding glancing angles, for X-rays having energies equivalent to those of the $\mathrm{P} \mathrm{K}$ - and $\mathrm{La} \mathrm{L}_{3}$-edge were calculated using a web-based program and are presented in Table $2[43]$.

The P $\mathrm{K}$ - and $\mathrm{La} \mathrm{L}_{3}$-edge GA-XANES spectra from the ion-implanted materials were collected in partial fluorescent yield (PFY) mode and total electron yield (TEY) mode; however, the TEY signal suffered from charging effects. An attempt was made to reduce charging effects in the GA-XANES spectra collected in TEY mode by connecting the surface of the pellet to the electrically grounded $\mathrm{Cu}$ sample holder using Ag paint. Nevertheless, the TEY signal from the $\mathrm{P}$ K-edge spectra still exhibited signs of severe charging in this material. A moderate TEY signal was obtained for certain compositions in the case of the higher energy $\mathrm{La} \mathrm{L}_{3}$-edge spectra. It should be noted that the PFY signals from white-line $\mathrm{La} \mathrm{L}_{3}$-edge spectra were distorted by absorption effects so only the TEY spectra that were successfully collected were analyzed. P Kedge spectra were calibrated by collecting the spectrum from red P (Alfa Aesar; 99\%) with the maximum in the first derivative of the $\mathrm{P}$ K-edge set to $2145.5 \mathrm{eV}$ [44]. La $\mathrm{L}_{3}$-edge XANES spectra were calibrated using the spectrum from $\mathrm{Cr}$ metal by setting the maximum in the first derivative of the $\mathrm{Cr}$ K-edge to $5989 \mathrm{eV}$ [43]. All XANES spectra were analyzed using the Athena software program [45].

\subsection{2. $P L_{2,3}$-edge XANES}

P L $\mathrm{L}_{2,3}$-edge XANES spectra were also collected from the ion-implanted $\mathrm{La}_{1-\mathrm{x}} \mathrm{Yb}_{\mathbf{X}} \mathrm{PO}_{4}$ materials using the Variable Line Spacing-Plane Grating Monochromator (VLS-PGM; 11ID-2) 
beamline located at the CLS [46]. The ion-implanted pellets were mounted on carbon tape and the spectra were measured in vacuum in total fluorescence yield (TFY) mode. These spectra were not collected using a glancing angle geometry. The $\mathrm{P} \mathrm{L}_{2,3}$-edge XANES spectra were calibrated using red $\mathrm{P}$, with the $\mathrm{P} \mathrm{L}_{2,3}$-edge absorption energy set to $130 \mathrm{eV}$.

\section{Results and discussion}

\subsection{Bulk and micro X-ray diffraction}

Bulk powder XRD patterns from the as-synthesized $\mathrm{La}_{1-\mathrm{x}} \mathrm{Yb}_{\mathrm{x}} \mathrm{PO}_{4}(\mathrm{x}=0.0,0.3,0.7$, and 1.0) materials are presented in Figure 3 along with the $\mu$-XRD patterns from the $\mathrm{Au}^{-}$ionimplanted $\mathrm{La}_{1-\mathrm{x}} \mathrm{Yb}_{\mathrm{x}} \mathrm{PO}_{4}$ materials (doses: $1 \times 10^{14}, 5 \times 10^{14}$, and $1 \times 10^{15}$ ions $/ \mathrm{cm}^{2}$ ). The endmembers of the $\mathrm{La}_{1-\mathrm{x}} \mathrm{Yb}_{\mathrm{x}} \mathrm{PO}_{4}$ series adopt the lower symmetry monazite $(\mathrm{x}=0)$ structure or the higher symmetry xenotime $(\mathrm{x}=1)$ structure, respectively [33]. It is to be noted that the powder XRD pattern of $\mathrm{YbPO}_{4}$ showed the presence of a minor amount of $\mathrm{Yb}_{2} \mathrm{O}_{3}$ (indicated by a diamond symbol in Figure 3b) in addition to the predominant xenotime phase. However, the presence of this low concentration impurity does not impact the analysis of the XANES spectra. At intermediate values of $x(x=0.3$ and 0.7$)$, the materials exist as a mixture of both the monazite and xenotime phases [33]. Information about the lattice constants and relative concentration of monazite and xenotime phases were obtained from the Rietveld refined powder $\mathrm{XRD}$ data from $\mathrm{La}_{1-\mathrm{x}} \mathrm{Yb}_{\mathrm{x}} \mathrm{PO}_{4}$ (Table $\mathrm{S} 1$ in Supporting Information) [33]. It was assumed in this study that the composition of the monazite structure was $\mathrm{LaPO}_{4}$ while the composition of the xenotime structure was $\mathrm{YbPO}_{4}$ because of the poor solubility of $\mathrm{Yb}$ in the monazite structure (and vice versa for $\mathrm{La}$ in the xenotime structure) [9]. The general trend in the $\mathrm{La}_{1-\mathrm{x}} \mathrm{Yb}_{\mathrm{x}} \mathrm{PO}_{4}$ series 
is that the relative concentration of the xenotime structure increases with greater $\mathrm{Yb}$ concentration (see Table S1 in the supporting information) [33].

Powder patterns collected using the $\mu$-XRD set-up from the ion-implanted materials allowed for a qualitative examination of how the long-range structure of these materials were affected by ion-implantation. In comparison to the powder XRD patterns from the as-synthesized materials, the $\mu$-XRD patterns from the ion-implanted $\mathrm{La}_{1-\mathrm{x}} \mathrm{Yb}_{\mathrm{x}} \mathrm{PO}_{4}$ materials exhibited broader diffraction peaks (Figure 3). This observation indicates that the structure of the materials were damaged as a result of ion-implantation. The full width at half maximum (FWHM) values of the ( $\left.\begin{array}{lll}0 & 2 & -1\end{array}\right)$ and ( $\left.\begin{array}{lll}0 & 2 & 0\end{array}\right)$ reflections from the as-synthesized and ion-implanted $\mathrm{La}_{1-\mathrm{x}} \mathrm{Yb}_{\mathrm{x}} \mathrm{PO}_{4}$ materials are listed in Table 3. The ( $\left.\begin{array}{lll}0 & 2 & -1\end{array}\right)$ peak is characteristic of the monazite phase while the $\left(\begin{array}{lll}0 & 2 & 0\end{array}\right)$ peak is characteristic of the xenotime phase. The FWHM values of the characteristic peaks from the as-synthesized compounds were obtained from the bulk powder XRD data. Diffraction peaks can broaden because of the creation of defects (e.g., interstitials and vacancies) and/or because of a reduction in the average crystallite size $[47,48]$. It is believed that both effects have resulted in the increased width of the diffraction peaks from the ion-implanted materials. Although peak broadening is observed in the $\mu$-XRD patterns from ion-implanted $\mathrm{La}_{1-\mathrm{x}} \mathrm{Yb}_{\mathrm{x}} \mathrm{PO}_{4}(\mathrm{x}=0.0,0.3$, 0.7 , and 1.0), shifts in the $2 \theta$ peak positions were not observed between the ion implanted and assynthesized materials (Figure 3).

One of the $2 \theta$ peaks (marked with an asterisk symbol in Figure $3 d$ ) in the $\mu$-XRD pattern from $\mathrm{La}_{0.3} \mathrm{Yb}_{0.7} \mathrm{PO}_{4}$ that was implanted with ions to the highest dose $\left(1 \times 10^{15} \mathrm{ions} / \mathrm{cm}^{2}\right)$ was observed to be more intense in comparison to the diffraction pattern from $\mathrm{La}_{0.3} \mathrm{Yb}_{0.7} \mathrm{PO}_{4}$ that was implanted to a lower dose. This observation may be attributed to preferential orientation effects (Figure 3d). Examination of the $\mu$-XRD pattern from $\mathrm{YbPO}_{4}$ that was implanted with ions at the 
highest dose $\left(1 \times 10^{15}\right.$ ions $\left./ \mathrm{cm}^{2}\right)$ revealed the presence of an anomalous peak (marked with a dot symbol in Figure 3b). This peak is not due to the xenotime structure or any of the unreacted starting materials and the underlying reason for the appearance of this peak is unknown.

\subsection{P K-edge GA-XANES: Ion implanted $\mathrm{La}_{1-\mathrm{x}} \mathrm{Yb}_{\mathrm{x}} \mathrm{PO}_{4}$}

Normalized P K-edge XANES spectra that represent the transition of electrons from the P 1s state to $\mathrm{P} 3 p$ conduction states were collected from the ion-implanted $\mathrm{La}_{1-\mathrm{x}} \mathrm{Yb}_{\mathrm{x}} \mathrm{PO}_{4}(\mathrm{x}=0.0$, $0.3,0.7,1.0)$ materials at various glancing angles to study the extent of structural damage as a function of depth, implantation dose $\left(1 \times 10^{14}, 5 \times 10^{14}\right.$, and $1 \times 10^{15}$ ions $\left./ \mathrm{cm}^{2}\right)$, and composition (Figures 4-7). The $\mathrm{P}$ K-edge spectra from the as-synthesized $\mathrm{La}_{1-\mathrm{x}} \mathrm{Yb}_{\mathrm{x}} \mathrm{PO}_{4}$ materials are also included in Figures 4-7 [33].

The P K-edge GA-XANES spectra from ternary $\mathrm{LaPO}_{4}$ (monazite) implanted with $\mathrm{Au}^{-}$ ions to a dose of $5 \times 10^{14}$ and $1 \times 10^{15}$ ions $/ \mathrm{cm}^{2}$ are presented in Figure 4. A significant change in the spectral lineshape is observed as a result of ion-implantation and the glancing angle used to collect the spectra; however, no significant differences in the spectra were observed depending on ion dose. Relative to the spectra from as-synthesized $\mathrm{LaPO}_{4}$, the $\mathrm{P} \mathrm{K}$-edge spectra from the ion-implanted materials clearly exhibit a loss of both intensity and fine structure. The near-edge region of the spectra was broader as a result of ion-implantation, and it is proposed that this is due to a distortion of the $\mathrm{PO}_{4}$ coordination environment (Figures $4 \mathrm{a}$ and $4 \mathrm{~b}$ ).

Normalized P K-edge GA-XANES spectra from ion-implanted $\mathrm{YbPO}_{4}$ (xenotime) are shown along with the spectrum from the as-synthesized material in Figure 5. Unlike $\mathrm{LaPO}_{4}$, the structural response of $\mathrm{YbPO}_{4}$ towards the lowest $\left(1 \times 10^{14}\right.$ and $5 \times 10^{14}$ ions $\left./ \mathrm{cm}^{2}\right)$ and highest ionimplantation doses $\left(1 \times 10^{15} \mathrm{ions} / \mathrm{cm}^{2}\right)$ was found to be different (Figure 5). The spectral lineshape 
of the sample that received the highest ion-implantation dose showed some resemblance to the lineshape of the spectrum from the as-synthesized material whereas the samples that were exposed to a lower dose did not (Figure 5c). This observation is based on the presence of fine structure in the spectrum from $\mathrm{YbPO}_{4}$ exposed to the highest ion-implantation dose, which is similar but less intense than the fine structure observed in the spectrum from as-synthesized $\mathrm{YbPO}_{4}$ (see arrow in Figure 5c). The fine structure was observed only at the lowest glancing angles $\left(23^{\circ}-250 \mathrm{~nm} ; 44.6^{\circ}-450 \mathrm{~nm}\right.$; see Figure $\left.5 \mathrm{c}\right)$. Based on these observations, it is suggested that a high flux of $\mathrm{Au}^{-}$ions (i.e., $1 \times 10^{15}$ ions $/ \mathrm{cm}^{2}$ ) may induce partial recrystallization of the damaged xenotime $\left(\mathrm{YbPO}_{4}\right)$ material. Although no sign of structural recovery was observed in the spectrum from $\mathrm{LaPO}_{4}$ implanted to a dose of $1 \times 10^{15} \mathrm{ions} / \mathrm{cm}^{2}$, the authors cannot completely rule out the possibility of partial recrystallization of the damaged monazite structure (Figure 4b). Unlike the spectrum from $\mathrm{YbPO}_{4}$ which adopts the xenotime structure, the XANES spectrum from as-synthesized $\mathrm{LaPO}_{4}$ is not structurally rich (i.e., less fine structure is observed), so minor changes in the spectrum depending on ion dose would be difficult to observe.

The partial self-healing of ion-implanted materials at room temperature could be explained using the "loading-unloading" effect [49,50]. It has been reported previously that nanomaterials (e.g., $\mathrm{MgGa}_{2} \mathrm{O}_{4}$ and $\mathrm{ZrO}_{2}$ ) exhibit greater resistance to radiation-induced structural damage and theoretical studies have investigated the mechanism for the radiation-resistance of these materials [49-52]. Radiation-induced structural damage can lead to the production of defects such as interstitial atoms and vacancies $[49,53]$. The grain boundaries present in the material traps the interstitial atom and releases it when there are enough vacancies in the vicinity of the grain boundary $[49,50]$. In this way, the vacancies are annihilated and the material is able to selfheal from the structural damage $[49,50]$. The high dose of $\mathrm{Au}^{-}$ions $\left(1 \times 10^{15} \mathrm{ions} / \mathrm{cm}^{2}\right)$ that were 
used to implant $\mathrm{YbPO}_{4}$ material may have also resulted in local heating of the sample with the accompanying rise in temperature providing enough energy for the movement of displaced atoms and the partial recovery of the structure $[54,55]$.

P K-edge GA-XANES spectra were also collected from ion-implanted and as-synthesized quaternary $\mathrm{La}_{1-\mathrm{x}} \mathrm{Yb}_{\mathrm{x}} \mathrm{PO}_{4}(\mathrm{x}=0.3$ and 0.7$)$ materials to understand the effect of heavy/light rareearth substitution on the structural stability of monazite/xenotime structures (Figures 6 and 7). The relative percent composition of monazite and xenotime phases in as-synthesized $\mathrm{La}_{0.7} \mathrm{Yb}_{0.3} \mathrm{PO}_{4}$ (Monazite - 70\%; Xenotime - 30\%) and $\mathrm{La}_{0.3} \mathrm{Yb}_{0.7} \mathrm{PO}_{4}$ (Monazite - 25\%; Xenotime - 76\%) compounds were determined previously by Rietveld refinement of powder XRD data as well as from a linear combination fitting (LCF) of P K-edge XANES spectra [33]. The P K-edge XANES spectrum from as-synthesized $\mathrm{La}_{0.3} \mathrm{Yb}_{0.7} \mathrm{PO}_{4}$ exhibited more fine structure in comparison to the spectrum from $\mathrm{La}_{0.7} \mathrm{Yb}_{0.3} \mathrm{PO}_{4}$ due to the higher concentration of the xenotime structure. After ion-implantation, $\mathrm{La}_{0.7} \mathrm{Yb}_{0.3} \mathrm{PO}_{4}$ and $\mathrm{La}_{0.3} \mathrm{Yb}_{0.7} \mathrm{PO}_{4}$ were structurally damaged as observed by changes in the spectral lineshape of the P K-edge spectra (Figure 6). Similar to $\mathrm{LaPO}_{4}$, the P K-edge of ion-implanted $\mathrm{La}_{0.7} \mathrm{Yb}_{0.3} \mathrm{PO}_{4}$ did not exhibit a varied structural response to different ion-implantation doses (Figure 6). However, the results obtained for ionimplanted $\mathrm{La}_{0.3} \mathrm{Yb}_{0.7} \mathrm{PO}_{4}$ are similar to those obtained for ion-implanted $\mathrm{YbPO}_{4}$ (Figure 7). At the highest dose $\left(1 \times 10^{15}\right.$ ions $\left./ \mathrm{cm}^{2}\right)$, the $\mathrm{Yb}$-rich compound exhibited signs of partial structural recovery as indicated by the appearance of fine structure in the P K-edge spectra (see arrow in Figure $7 \mathrm{c}$ ). No signs of structural recovery were observed when $\mathrm{La}_{0.3} \mathrm{Yb}_{0.7} \mathrm{PO}_{4}$ was implanted to lower doses $\left(1 \times 10^{14}\right.$ and $5 \times 10^{14}$ ions $/ \mathrm{cm}^{2}$; Figures $7 \mathrm{a}$ and $\left.7 \mathrm{~b}\right)$. 


\subsection{P K-edge GA-XANES: Thermal annealing of ion implanted $\mathrm{La}_{1-\mathrm{x}} \mathrm{Yb}_{\mathrm{X}} \mathrm{PO}_{4}$}

As described in Section 3.2, the $\mathrm{La}_{1-\mathrm{x}} \mathrm{Yb}_{\mathrm{x}} \mathrm{PO}_{4}$ materials are not resistant to radiationinduced structural damage. Actinides, in general, produce high levels of heat during the radioactive decay process in addition to the production of high energy recoil daughter product nuclides and $\alpha$-particles $[14,56]$. However, depending on the composition of the crystalline wasteform, the heat released during the radioactive decay process could promote structural reorganization of the damaged material [57].

P K-edge GA-XANES spectra were collected from the ion-implanted $\mathrm{La}_{1-\mathrm{x}} \mathrm{Yb}_{\mathrm{x}} \mathrm{PO}_{4}(\mathrm{x}=$ $0.0,0.3,0.7,1.0)$ materials after annealing them to $300^{\circ}$ or $900^{\circ} \mathrm{C}$ to study the heat-induced recovery process of these materials. (It should be noted that not all ion-implanted materials were implanted to the same dose before annealing.) The P K-edge XANES spectra collected from the annealed materials using the lowest glancing angles are shown in Figure 8. The P K-edge GAXANES spectra from ion-implanted $\mathrm{LaPO}_{4}$ before and after annealing to $300^{\circ}$ or $900^{\circ} \mathrm{C}$ are shown in Figure 8a along with the spectrum from as-synthesized $\mathrm{LaPO}_{4}$. The annealed ionimplanted $\mathrm{LaPO}_{4}$ samples showed signs of partial structural recovery as indicated by the increase in intensity and decrease in width of the near-edge region in comparison to the spectrum from ion-implanted $\mathrm{LaPO}_{4}$. Although significant differences in the spectral lineshape were observed between the ion-implanted and annealed ion-implanted $\mathrm{LaPO}_{4}$ materials, no major differences in the spectra were observed between the two annealing temperatures (i.e., $300^{\circ} \mathrm{C}$ vs. $900^{\circ} \mathrm{C}$ ).

The effect of temperature on the structural recovery of damaged $\mathrm{YbPO}_{4}$ was also studied using $\mathrm{P}$ K-edge GA-XANES (Figure 8b). The spectrum from $\mathrm{YbPO}_{4}$ annealed at $300^{\circ} \mathrm{C}$ revealed only minor indications of structural recovery. However, the structure of $\mathrm{YbPO}_{4}$ was 
observed to recover to its original state after annealing the material to $900^{\circ} \mathrm{C}$ (see Figure $8 \mathrm{~b}$ ). The difference in behaviour between $\mathrm{LaPO}_{4}$ and $\mathrm{YbPO}_{4}$ may be attributed to the $\mathrm{LaPO}_{4}$ sample receiving a higher dose of ions as well as the different structures adopted by these materials. The P K-edge GA-XANES spectra from the $\mathrm{La}_{0.7} \mathrm{Yb}_{0.3} \mathrm{PO}_{4}$ and $\mathrm{La}_{0.3} \mathrm{Yb}_{0.7} \mathrm{PO}_{4}$ materials that were ionimplanted to the same dose $\left(5 \times 10^{14}\right.$ ions $\left./ \mathrm{cm}^{2}\right)$ and then annealed also displayed signs of structural recovery (Figures $8 \mathrm{c}$ and $8 \mathrm{~d}$ ). Had there been any surface segregation of phases in these quaternary compounds it would be expected that only one phase would recover from the structural damage. However, both the monazite and xenotime structures partially recover from the structural damage as indicated by the similarity of the spectral lineshape to that of the assynthesized material. The signs of recovery were more evident in the spectra from the ionimplanted materials annealed at the highest temperature $\left(900^{\circ} \mathrm{C}\right)$; however, structural recovery was not complete. This conclusion is a result of the differences in the intensity of the P K-edge GA-XANES spectra between the as-synthesized and annealed ion-implanted materials (See Figures 8c and 8d).

\subsection{P L2,3-edge XANES}

The normalized $\mathrm{P} \mathrm{L}_{2,3}$-edge XANES spectra from ion-implanted $\mathrm{La}_{1-\mathrm{x}} \mathrm{Yb}_{\mathrm{x}} \mathrm{PO}_{4}$ are shown in Figure 9 along with the spectra from the as-synthesized materials. The $\mathrm{P}_{2,3}$-edge spectrum generally represents the transition of electrons from the $\mathrm{P} 2 \mathrm{p}$ state to $\mathrm{P} 3 \mathrm{~s}$ and $3 \mathrm{~d}$ conduction states [58]. In a previous study, the two distinct features observed in the $\mathrm{P} \mathrm{L}_{2,3}$-edge spectra from as-synthesized $\mathrm{La}_{1-\mathrm{x}} \mathrm{Yb}_{\mathrm{x}} \mathrm{PO}_{4}(\mathrm{~A}$ and $\mathrm{B})$ were assigned to the transition of $\mathrm{P} 2 \mathrm{p}$ electrons into the overlapping P 3s and 3d states [33]. Similar to P K-edge GA-XANES spectra, the P L 2,3 -edge spectra were observed to be sensitive to changes in the local coordination environment of $\mathrm{P}$ as a result of ion-implantation. Relative to the as-synthesized materials, the lineshape of the spectra 
from the ion-implanted $\mathrm{La}_{1-\mathrm{x}} \mathrm{Yb}_{\mathrm{x}} \mathrm{PO}_{4}(\mathrm{x}=0,0.3,0.7,1.0)$ materials changed significantly (see Figure 9). The increased broadness of the spectra from the ion-implanted materials implies that the degeneracy of the $\mathrm{P}$ conduction states is lost as a result of ion-implantation.

The $\mathrm{P} \mathrm{L}_{2,3}$-edge spectra from the ion-implanted $\mathrm{La}_{1-\mathrm{x}} \mathrm{Yb}_{\mathrm{x}} \mathrm{PO}_{4}(\mathrm{x}=0.3$ and 0.7$)$ materials that were annealed at $300^{\circ}$ and $900^{\circ} \mathrm{C}$ are shown in Figure 10 . The near-edge region in the $\mathrm{P} \mathrm{L}_{2,3-}$ edge spectra from the ion-implanted $\mathrm{La}_{1-\mathrm{x}} \mathrm{Yb}_{\mathrm{x}} \mathrm{PO}_{4}(\mathrm{x}=0.3$ and 0.7$)$ materials becomes narrower with increasing annealing temperature, which is a result of the partial recovery of the structure of these materials. Considerable differences in the spectral lineshape were observed between the two annealing temperatures and it was observed that the spectral lineshape of ion-implanted $\mathrm{La}_{0.7} \mathrm{Yb}_{0.3} \mathrm{PO}_{4}$ and $\mathrm{La} 0.3 \mathrm{Yb}_{0.7} \mathrm{PO}_{4}$ annealed at the highest temperature $\left(900^{\circ} \mathrm{C}\right)$ closely resembled that of the as-synthesized material (Figure 10). These observations are in agreement with those obtained by the examination of the P K-edge GA-XANES spectra from the annealed ionimplanted materials (See Section 3.3).

\section{5. $\mathrm{La} \mathrm{L}_{3}$-edge XANES}

La $\mathrm{L}_{3}$-edge GA-XANES spectra were collected from the ion-implanted $\mathrm{La}_{1-\mathrm{x}} \mathrm{Yb}_{\mathrm{x}} \mathrm{PO}_{4}$ materials to examine changes in the local coordination environment of $\mathrm{La}$. The $\mathrm{La}_{3}$-edge partial fluorescent yield (PFY) spectra were distorted because of severe absorption effects so the total electron yield (TEY) mode was the preferred method of detection $[59,60]$. The TEY La L $\mathrm{L}_{3}$ edge XANES spectra from the ion-implanted $\mathrm{La}_{0.7} \mathrm{Yb}_{0.3} \mathrm{PO}_{4}$ and $\mathrm{La}_{0.3} \mathrm{Yb}_{0.7} \mathrm{PO}_{4}$ materials are shown in Figure 11 along with the spectra from the as-synthesized materials. The white-line feature in the $\mathrm{La} \mathrm{L}_{3}$-edge spectra represents a $2 p \rightarrow 5 \mathrm{~d}$ excitation [61]. After ion-implantation, the intensity of the $\mathrm{La} \mathrm{L}_{3}$-edge decreased relative to the as-synthesized material and the spectra 
became broader [61, 62]. This observation suggests a distortion of the La coordination environment in the ion-implanted materials (Figures 11a and 11b) [61,62]. Since the changes in the intensity of the $\mathrm{La} \mathrm{L}_{3}$-edge between the as-synthesized and ion-implanted materials were observed to be minor, $\mathrm{Yb} \mathrm{L}_{3}$-edge spectra were not collected from the ion-implanted materials as they would be expected to give similar information as the $\mathrm{La}_{2}$-edge spectra.

\section{Conclusion}

The effect of $\mathrm{Au}^{-}$ion-implantation on the long- and short-range order of $\mathrm{La}_{1-\mathrm{x}} \mathrm{Yb}_{\mathbf{x}} \mathrm{PO}_{4}$ materials was studied using $\mu$-XRD and GA-XANES. The $\mu$-XRD data revealed the loss of longrange order in the $\mathrm{La}_{1-\mathrm{x}} \mathrm{Yb}_{\mathrm{x}} \mathrm{PO}_{4}$ materials that were implanted with $2 \mathrm{MeV} \mathrm{Au}^{-}$ions. The $\mathrm{P} \mathrm{K}-, \mathrm{P}$ $\mathrm{L}_{2,3}$, and $\mathrm{La} \mathrm{L}_{3}$-edge XANES spectra clearly showed that the $\mathrm{La}_{1-\mathrm{x}} \mathrm{Yb}_{\mathrm{x}} \mathrm{PO}_{4}$ materials are susceptible to radiation-induced structural damage. The $\mathrm{P} \mathrm{K}$ - and $\mathrm{La} \mathrm{L}_{3}$-edge GA-XANES and $\mathrm{P}$ $\mathrm{L}_{2,3}$-edge XANES spectra were observed to be very sensitive to changes in the structure of these materials as a result of ion-implantation. The P K-edge GA-XANES spectra provided evidence for the occurrence of partial recrystallization of the structure of the $\mathrm{La}_{0.3} \mathrm{Yb}_{0.7} \mathrm{PO}_{4}$ and $\mathrm{YbPO}_{4}$ materials that were implanted to $\mathrm{Au}^{-}$ions to the highest dose $\left(1 \times 10^{15}\right.$ ions $\left./ \mathrm{cm}^{2}\right)$. Annealing studies of the ion-implanted $\mathrm{La}_{1-\mathrm{x}} \mathrm{Yb}_{\mathrm{x}} \mathrm{PO}_{4}$ materials have shown the ability of these materials to recover (either partially or completely depending on composition) from structural damage caused by the implantation of high-energy $\mathrm{Au}^{-}$ions. It was found in this study that the ability of ionimplanted rare-earth phosphates to recover from a damaged state is dependent on the ion-dose received and the temperature that these materials are exposed to post implantation. 


\section{Acknowledgements}

The Natural Sciences and Engineering Research Council (NSERC) of Canada funded this project through a discovery grant awarded to APG. MRR thanks the University of Saskatchewan for financial support. The Canadian Foundation for Innovation (CFI) is thanked for providing funds to purchase the PANalytical Empyrean powder X-ray diffractometer that was used in this project. Mr. Jack Hendriks is thanked for carrying out the ion-implantation studies using the Tandetron accelerator located at Interface Science Western, University of Western Ontario. J. R. Hayes and E. R. Aluri from the Department of Chemistry, University of Saskatchewan are thanked for help in the collection of the XANES spectra presented in this study. Dr. Yongfeng $\mathrm{Hu}$, Ms. Aimee MacLennan, and Dr. Lucia Zuin of the CLS are thanked for their support in carrying out XANES experiments at beamlines 06B1-1 and 11ID-2. The CLS is supported by NSERC, the National Research Council of Canada, the Canadian Institutes of Health Research,

the Province of Saskatchewan, Western Economic Diversification Canada, and the University of Saskatchewan.

Supporting Information: Rietveld refinement results from $\mathrm{La}_{1-\mathrm{x}} \mathrm{Yb}_{\mathrm{x}} \mathrm{PO}_{4}(\mathrm{x}=0,0.3,0.7,1.0)$; Ion-implantation depth profiles and plots showing the number of vacancies per $\mathrm{Au}^{-}$ion from $\mathrm{LaPO}_{4}, \mathrm{La}_{0.3} \mathrm{Yb}_{0.7} \mathrm{PO}_{4}$ and $\mathrm{YbPO}_{4}$. 


\section{References}

[1] G. R. Lumpkin, Ceramic Waste Forms for Actinides, Elements 2 (2006) 365-372.

[2] W. E. Lee, M. Gilbert, S. T. Murphy, R. W. Grimes, Opportunities for Advanced Ceramics and Composites in the Nuclear Sector, J. Am. Ceram. Soc. 96 (2013) 2005-2030.

[3] D. Men, M. K. Patel, I. O. Usov, M. Toiammou, I. Monnet, J. C. Pivin, J. R. Porter, M. L. Mecartney, Radiation Damage in Multiphase Ceramics, J. Nucl. Mater. 443 (2013) 120-127.

[4] R. C. Ewing, W. J. Weber, F. W. Clinard Jr, Radiation Effects in Nuclear Waste Forms for High-Level Radioactive Waste, Prog. Nucl. Energy 29 (1995) 63-127.

[5] A. Meldrum, L. A. Boatner, R. C. Ewing, A Comparison of Radiation Effects in Crystalline $\mathrm{ABO}_{4}$-type Phosphates and Silicates, Mineral. Mag. 64 (2000) 185-194.

[6] A. Meldrum, L. A. Boatner, R.C. Ewing, Displacive Radiation Effects in the Monazite- and Zircon- Structure Orthophosphates, Phys. Rev. B: Condens. Matter Mater. Phys. 56 (1997) $13805-13814$.

[7] B. V. Emden, M. R. Thornber, J. Graham, F. J. Lincoln, The Incorporation of Actinides in Monazite and Xenotime from Placer Deposits in Western Australia, Can. Mineral. 35 (1997) 95-104.

[8] R. Gratz, W. Heinrich, Monazite-Xenotime Thermobarometry; Experimental Calibration of the Miscibility Gap in the Binary System $\mathrm{CePO}_{4}-\mathrm{YPO}_{4}$, Am. Mineral. 82 (1997) 772-780.

[9] Y. Ni, J. M. Hughes, A. N. Mariano, Crystal Chemistry of the Monazite and Xenotime Structures, Am. Mineral. 80 (1995) 21-26.

[10] G. W. Beall, L. A. Boatner, D. F. Mullica, W. O. Milligan, The Structure of Cerium Orthophosphate, a Synthetic Analogue of Monazite, J. Inorg. Nucl. Chem. 43 (1981) 101-105. 
[11] W. O. Milligan, D. F. Mullica, G. W. Beall, L. A. Boatner, Structural Investigations of YPO 4 , $\mathrm{ScPO}_{4}$, and $\mathrm{LuPO}_{4}$, Inorg. Chim. Acta. 60 (1982) 39-43.

[12] N. Clavier, R. Podor, N. Dacheux, Crystal Chemistry of the Monazite Structure, J. Eur. Ceram. Soc. 31 (2011) 941-976.

[13] D. F. Mullica, W. O. Milligan, D. A. Grossie, G. W. Beall, L. A. Boatner, Ninefold Coordination in $\mathrm{LaPO}_{4}$ : Pentagonal Interpenetrating Tetrahedral Polyhedron, Inorg. Chim. Acta. 95 (1984) 231-236.

[14] W. J. Weber, R. C. Ewing, C. R. A. Catlow, T. Diaz de la Rubia, L. W. Hobbs, C. Kinoshita, Hj. Matzke, A. T. Motta, M. Nastasi, E. K. H. Salje, et al., Radiation Effects in Crystalline Ceramics for the Immobilization of High-Level Nuclear Waste and Plutonium, J. Mater. Res. 13 (1998) 1434-1484.

[15] R. C. Ewing, A. Meldrum, L. Wang, S. Wang, Radiation-Induced Amorphization, Rev. Mineral. Geochem. 39 (2000) 319-361.

[16] R. C. Ewing, R. F. Haaker, W. Lutze, Leachability of Zircon as a Function of Alpha Dose. Mater. Res. Soc. Symp. Proc. 11 (1982) 389-396.

[17] B. C. Sales, C. W. White, L. A. Boatner, A Comparison of the Corrosion Characteristics of Synthetic Monazite and Borosilicate Glass Containing Simulated Nuclear Defense Waste, Nucl. Chem. Waste Management. 4 (1983) 281-289.

[18] R. C. Ewing, L. Wang, Phosphates as Nuclear Waste Forms, Rev. Mineral. Geochem. 48 (2002) 673-699.

[19] K. Bakker, H. Hein, R. J. M. Konings, R. R. van der Laan, Hj. Matzke, P. van Vlaanderen, Thermophysical Property Measurements and Ion-Implantation Studies on $\mathrm{CePO}_{4}$, J. Nucl. Mater. 252 (1998) 228. 
[20] F. Demartin, T. Pilati, V. Diella, S. Donzelli, P. Gentile, C. M. Gramaccioli, The Chemical Composition of Xenotime from Fissures and Pegmatites in the Alps, Can. Mineral. 29 (1991) $69-75$.

[21] A. Meldrum, L. A. Boatner, W. J. Weber, R. C. Ewing, Radiation Damage in Zircon and Monazite, Geochimica et Cosmochimica Acta. 62 (1998) 2509-2520.

[22] H. Schlenz, J. Heuser, A. Neumann, S. Schmitz, D. Bosbach, Monazite as a Suitable Actinide Waste Form, Z. Kristallogr. 228 (2013) 113-123.

[23] V. S. Urusov, A. E. Grechanovsky, N. N. Eremin, Radiation Resistance of the Xenotime $\mathrm{YPO}_{4}$ from the Computer Simulation Data, Glass Phys. Chem. 38 (2012) 55-62.

[24] B. E. Burakov, M. A. Yagovkina, V. M. Garbuzov, A. A. Kitsay, V. A. Zirlin, SelfIrradiation of Monazite Ceramics: Contrasting Behavior of $\mathrm{PuPO}_{4}$ and $(\mathrm{La}, \mathrm{Pu}) \mathrm{PO}_{4}$ Doped with Pu-238, MRS Proceedings, 824, Boston, 2004.

[25] V. Picot, X. Deschanels, S. Peuget, B. Glorieux, A. M. Seydoux-Guillaume, R. Wirth, Ion Beam Radiation Effects in Monazite, J. Nucl. Mater. 381 (2008) 290-296.

[26] A. Meldrum, L. A. Boatner, L. M. Wang, R. C. Ewing, Ion-Beam-Induced Amorphization of $\mathrm{LaPO}_{4}$ and $\mathrm{ScPO}_{4}$, Nucl. Instrum. Methods Phys. Res., Sect. B. 127 (1997) 160-165.

[27] X. Deschanels, A. M. Seydoux-Guillaume, V. Magnin, A. Mesbah, M. Tribet, M. P. Moloney, Y. Serruys, S. Peuget, Swelling Induced by Alpha Decay in Monazite and Zirconolite Ceramics: A XRD and TEM Comparative Study, J. Nucl. Mat. 448 (2014) 184194.

[28] F. G. Karioris, L. Cartz, K. A. Gowda, Heavy Ion Bombardment of Monoclinic $\mathrm{ThSiO}_{4}$, $\mathrm{ThO}_{2}$ and Monazite, Radiat. Eff. Lett. 58 (1981) 1-3. 
[29] A. M. Seydoux-Guillaume, R. Wirth, L. Nasdala, M. Gottschalk, J. M. Montel, W. Heinrich, An XRD, TEM and Raman Study of Experimentally Annealed Natural Monazite, Phys. Chem. Miner. 29 (2002) 240-253.

[30] L. Nasdala, R. Grotzschel, S. Probst, B. Bleisteiner, Irradiation Damage in Monazite-(Ce): An Example to Establish the Limits of Raman Confocality and Depth Resolution, Can. Mineral. 48 (2010) 351-359.

[31] E. R. Aluri, J. R. Hayes, J. D. S. Walker, A. P. Grosvenor, Investigation of The Structural Stability of Ion-Implanted $\mathrm{Gd}_{2} \mathrm{Ti}_{2-\mathrm{x}} \mathrm{Sn}_{\mathrm{x}} \mathrm{O}_{7}$ Pyrochlore-Type Oxides by Glancing Angle X-ray Absorption Spectroscopy, J. Phys. Chem. C. 118 (2014) 7910-7922.

[32] F. de Groot, High-Resolution X-ray Emission and X-ray Absorption Spectroscopy, Chem. Rev. 101 (2001) 1779-1808.

[33] M. R. Rafiuddin, E. Mueller, A. P. Grosvenor, X-ray Spectroscopic Study of the Electronic Structure of Monazite- and Xenotime-Type Rare-Earth Phosphates, J. Phys. Chem. C. 118 (2014) 18000-18009.

[34] G. A. Waychunas, Grazing-Incidence X-ray Absorption and Emission Spectroscopy, Rev. Mineral. Geochem. 49 (2002) 267-315.

[35] D. P. Reid, M. C. Stennett, B. Ravel, J. C. Woicik, N. Peng, E. R. Maddrell, N. C. Hyatt, The Structure of Ion Beam Amorphised Zirconolite Studied by Grazing Angle X-ray Absorption Spectroscopy, Nucl. Instrum. Methods Phys. Res., Sect. B. 268 (2010) 1847-1852.

[36] K. Momma; F. Izumi, VESTA: A Three-Dimensional Visualization System for Electronic and Structural Analysis, J. Appl. Crystallogr. 41 (2008) 653-658.

[37] X'pert HighScore Plus, Version 3.0, PANalytical B. V.: Almelo, The Netherlands, 2011. 
[38] J. F. Ziegler, J. P. Biersack, M. D. Ziegler, SRIM (The Stopping and Range of Ions in Matter), USA, 2013.

[39] J. R. Rustad, Density Functional Calculations of the Enthalpies of Formation of Rare-Earth Orthophosphates, Am. Mineral. 97 (2012) 791-799.

[40] F. X. Zhang, M. Lang, R. C. Ewing, J. Lian, Z. W. Wang, J. Hu, L. A. Boatner, PressureInduced Zircon-Type to Scheelite-Type Phase Transitions in $\mathrm{YbPO}_{4}$ and $\mathrm{LuPO}_{4}$, J. Solid State Chem. 181 (2008) 2633-2638.

[41] K. Trachenko, Understanding Resistance to Amorphization by Radiation Damage, J. Phys.: Condens. Matter 16 (2004) R1491-R1515.

[42] Y. F. Hu, I. Coulthard, D. Chevrier, G. Wright, R. Igarashi, A. Stinikov, B. W. Yates, E. L. Hallin,; T. K. Sham, R. Reininger, Preliminary Commissioning and Performance of the Soft X-ray Micro-characterization Beamline at the Canadian Light Source, AIP Conf. Proc. 1234 (2010) 343.

[43] X-ray attenuation length, http://henke.lbl.gov/optical_constants/atten2.html.

[44] A. Thompson, D. Attwood, E. Gullikson, M. Howells, K. J. Kim, J. Kirz, J. Kortright, I. Lindau, P. Pianetta, A. Robinson, et al., X-ray data booklet, Lawrence Berkeley National Laboratory, Berkeley, CA, 2009.

[45] B. Ravel, M. Newville, Athena, Artemis, Hephaestus: Data Analysis for X-ray Absorption Spectroscopy using IFEFFIT, J. Synchrotron Radiat. 12 (2005) 537-541.

[46] Y. F. Hu, L. Zuin, R. Reininger, T. K. Sham, VLS-PGM Beamline at the Canadian Light Source, AIP Conf. Proc. 879 (2007) 535.

[47] D. Balzar, X-ray Diffraction Line Broadening: Modeling and Applications to High- $\mathrm{T}_{\mathrm{c}}$ Superconductors, J. Res. Natl. Inst. Stand. Technol. 98 (1993) 321. 
[48] T. Ungar, Microstructural Parameters from X-ray Diffraction Peak Broadening, Scr. Mater. $51(2004) 777-781$.

[49] X. Bai, A. F. Voter, R. G. Hoagland, M. Nastasi, B. P. Uberuaga, Efficient Annealing of Radiation Damage Near Grain Boundaries via Interstitial Emission, Science 327 (2010) $1631-1634$.

[50] G. Ackland, Controlling Radiation Damage, Science 327 (2010) 1587-1588.

[51] T. D. Shen, S. Feng, M. Tang, J. A. Valdez, Y. Wang, K. E. Sickafus, Enhanced Radiation Tolerance in Nanocrystalline $\mathrm{MgAl}_{2} \mathrm{O}_{4}$, Appl. Phys. Lett. 90 (2007) 263115.

[52] F. Lu, Y. Shen, X. Sun, Z. Dong, R. C. Ewing, J. Lian, Size Dependence of RadiationInduced Amorphization and Recrystallization of Synthetic Nanostructured $\mathrm{CePO}_{4}$ Monazite, Acta Mater. 61 (2013) 2984-2992.

[53] G. D. Watkins, EPR Observation of Close Frenkel Pairs in Irradiated ZnSe, Phys. Rev. Lett. 33 (1974) 223.

[54] H. H. Tan, C. Jagadish, J. S. Williams, J. Zou, D. J. H. Cockayne, A. Sikorski, Ion Damage Buildup and Amorphization Processes in $\mathrm{Al}_{\mathrm{x}} \mathrm{Ga}_{1-\mathrm{x}} \mathrm{As}$, J. Appl. Phys. 77 (1995) 87.

[55] S. Margalit, Y. Nemirovsky, I. Rotstein, Electrical Properties of Ion-Implanted Layers in $\mathrm{Hg}_{0.79} \mathrm{Cd}_{0.21} \mathrm{Te}$, J. Appl. Phys. 50 (1979) 6386.

[56] R. C. Ewing, Long-Term Storage of Spent Nuclear Fuel, Nature Mater. 14 (2015) 252-257.

[57] D. Prieur, J. F. Vigier, T. Wiss, A. Janssen, J. Rothe, A. Cambriani, J. Somers, Structural Investigation of Self-Irradiation Damaged $\mathrm{AmO}_{2}$, J. Solid State Chem. 212 (2014) 7-12.

[58] J. Kruse, P. Leinweber, K. Eckhardt, F. Godlinski, Y. Hu, L. Zuin, P L2,3-Edge XANES: Overview of Reference Compounds, J. Synchrotron Radiat. 16 (2009) 247-259. 
[59] L. Troger, D. Aravanitis, K. Baberschke, H. Michaelis, U. Grimm, E. Zschech, Full Correction of the Self-Absorption in Soft-Fluorescence Extended X-ray-Absorption Fine Structure, Phys. Rev. B: Condens. Matter Mater. Phys. 46 (1992) 3283-3289.

[60] A. J. Achkar, T. Z. Regier, H. Wadati, Y. J. Kim, H. Zhang, D. G. Hawthorn, Bulk Sensitive X-ray Absorption Spectroscopy Free of Self-Absorption Effects, Phys. Rev. B: Condens. Matter Mater. Phys. 83 (2011) 081106-1 - 081106-4.

[61] H. Asakura, T. Shishido, K. Teramura, T. Tanaka, Local Structure and La $\mathrm{L}_{1}$ and $\mathrm{L}_{3}$-Edge XANES Spectra of Lanthanum Complex Oxides, Inorg. Chem. 53 (2014) 6048-6053.

[62] H. Asakura, T. Shishido, K. Teramura, T. Tanaka, Local Structure and $\mathrm{L}_{1}-$ and $\mathrm{L}_{3}$-Edge Xray Absorption Near-Edge Structure of Late Lanthanide Elements (Ho, Er, Yb), J. Phys. Chem. C. 119 (2015) 8070-8077. 
Tables

Table 1: Calculated electronic and nuclear stopping powers for $\mathrm{La}_{1-\mathrm{x}} \mathrm{Yb}_{\mathrm{x}} \mathrm{PO}_{4}$

\begin{tabular}{|c|c|c|c|c|}
\hline compound & crystal structure & $\begin{array}{c}\text { electronic } \\
\text { stopping power } \\
\mathrm{dE} / \mathrm{dx}_{\mathrm{e}}(\mathrm{eV} / \mathrm{nm})\end{array}$ & $\begin{array}{c}\text { nuclear stopping } \\
\text { power } \mathrm{dE} / \mathrm{dx}_{\mathrm{n}} \\
(\mathrm{eV} / \mathrm{nm})\end{array}$ & $\begin{array}{c}\text { electronic to } \\
\text { nuclear stopping } \\
\text { power ratio (ENSP) }\end{array}$ \\
\hline $\mathrm{LaPO}_{4}$ & Monazite & 2497 & 3873 & 0.645 \\
\hline $\mathrm{La}_{0.7} \mathrm{Yb}_{0.3} \mathrm{PO}_{4}$ & Monazite + Xenotime & 2747 & 4483 & 0.613 \\
\hline $\mathrm{La}_{0.3} \mathrm{Yb}_{0.7} \mathrm{PO}_{4}$ & Monazite + Xenotime & 2611 & 4571 & 0.571 \\
\hline $\mathrm{YbPO}_{4}$ & Xenotime & 2510 & 4639 & 0.541 \\
\hline
\end{tabular}


Table 2: Calculated X-ray attenuation depths and the corresponding glancing angles for the $P$ K- and $L \mathrm{~L}_{3}$ - edge GA-XANES spectra.

\begin{tabular}{|c|c|c|c|c|}
\hline \multirow[t]{2}{*}{ compounds } & \multicolumn{2}{|c|}{ P K-edge $(2145.5 \mathrm{eV})$} & \multicolumn{2}{|c|}{ La L $\mathrm{L}_{3}$-edge $(5483 \mathrm{eV})$} \\
\hline & glancing angle & $\begin{array}{c}\text { X-ray } \\
\text { attenuation } \\
\text { depth }(\mathrm{nm})\end{array}$ & glancing angle & $\begin{array}{c}\text { X-ray } \\
\text { attenuation } \\
\text { depth }(\mathrm{nm})\end{array}$ \\
\hline \multirow[t]{3}{*}{$\mathrm{LaPO}_{4}$} & $11.1^{\circ}$ & 250 & - & - \\
\hline & $20.3^{\circ}$ & 450 & - & - \\
\hline & $29.3^{\circ}$ & 638 & & \\
\hline \multirow[t]{3}{*}{$\mathrm{La}_{0.7} \mathrm{Yb}_{0.3} \mathrm{PO}_{4}$} & $15.7^{\circ}$ & 250 & $41.0^{\circ}$ & 3000 \\
\hline & $29.1^{\circ}$ & 450 & $85.0^{\circ}$ & 4560 \\
\hline & $43.6^{\circ}$ & 638 & & \\
\hline \multirow[t]{3}{*}{$\mathbf{L a}_{0.3} \mathrm{Yb}_{0.7} \mathbf{P O}_{4}$} & $19.8^{\circ}$ & 250 & $36.1^{\circ}$ & 3000 \\
\hline & $37.5^{\circ}$ & 450 & $85.0^{\circ}$ & 5074 \\
\hline & $59.8^{\circ}$ & 638 & & \\
\hline \multirow[t]{3}{*}{$\mathrm{YbPO}_{4}$} & $23.0^{\circ}$ & 250 & - & - \\
\hline & $44.6^{\circ}$ & 450 & - & - \\
\hline & $85.0^{\circ}$ & 639 & & \\
\hline
\end{tabular}


Table 3: Full width at half-maximium (FWHM) values of the ( $\left(\begin{array}{ll}2 & -1)\end{array}\right)$ [monazite] and ( $\left.\begin{array}{ll}0 & 0\end{array}\right)$ [xenotime] diffraction peaks from the damaged and as-synthesized $\mathrm{La}_{1-\mathrm{x}} \mathrm{Yb}_{\mathbf{x}} \mathrm{PO}_{4}$ materials.

\begin{tabular}{|c|c|c|c|c|}
\hline compound & $\begin{array}{c}\text { diffraction } \\
\text { peak }\end{array}$ & $\begin{array}{c}\text { FWHM } \\
\text { as-synthesized }\end{array}$ & $\begin{array}{c}\text { FWHM } \\
1 \times 10^{14} \text { ions } / \mathrm{cm}^{2}\end{array}$ & $\begin{array}{c}\text { FWHM } \\
1 \times 10^{15} \text { ions } / \mathrm{cm}^{2}\end{array}$ \\
\hline $\mathrm{LaPO}_{4}$ & $\left(\begin{array}{lll}0 & 2 & -1\end{array}\right)$ & $0.150^{\circ}$ & - & $0.385^{\circ}$ \\
\hline \multirow[t]{2}{*}{$\mathrm{La}_{0.7} \mathrm{Yb}_{0.3} \mathrm{PO}_{4}$} & $\left(\begin{array}{lll}0 & 2 & -1\end{array}\right)$ & $0.159^{\circ}$ & $0.374^{\circ}$ & $0.392^{\circ}$ \\
\hline & $\left(\begin{array}{lll}0 & 2 & 0\end{array}\right)$ & $0.142^{\circ}$ & $0.399^{\circ}$ & $0.367^{\circ}$ \\
\hline \multirow[t]{2}{*}{$\mathrm{La}_{0.3} \mathrm{Yb}_{0.7} \mathrm{PO}_{4}$} & $\left(\begin{array}{lll}0 & 2 & -1\end{array}\right)$ & $0.211^{\circ}$ & $0.462^{\circ}$ & $0.465^{\circ}$ \\
\hline & $\left(\begin{array}{lll}0 & 2 & 0\end{array}\right)$ & $0.160^{\circ}$ & $0.349^{\circ}$ & $0.368^{\circ}$ \\
\hline $\mathrm{YbPO}_{4}$ & $\left(\begin{array}{lll}0 & 2 & 0\end{array}\right)$ & $0.174^{\circ}$ & $0.360^{\circ}$ & $0.336^{\circ}$ \\
\hline
\end{tabular}




\section{Figure captions}

Figure 1: The crystal structures of (a) $\mathrm{CePO}_{4}\left(\right.$ Monazite $\left.-P 2_{1} / n\right)$ and (b) $\mathrm{YPO}_{4}($ Xenotime $I 4_{1} /$ amd) are shown with the c-axis directed into the page [33]. The crystal structures were generated using the VESTA program [36].

Figure 2: Ion-implantation depth profile of $\mathrm{La}_{0.7} \mathrm{Yb}_{0.3} \mathrm{PO}_{4}$ (black) calculated using the SRIM2013 software package [37]. A total of $5000 \mathrm{Au}^{-}$ions having an energy of $2 \mathrm{MeV}$ were used

during this calculation. A plot depicting the number of vacancies generated by the $\mathrm{Au}^{-}$ions as a function of depth is also shown in this figure.

Figure 3: $\mu$-XRD patterns from (a) $\mathrm{LaPO}_{4}$, (b) $\mathrm{YbPO}_{4}$, (c) $\mathrm{La}_{0.7} \mathrm{Yb}_{0.3} \mathrm{PO}_{4}$, and (d) $\mathrm{La}_{0.3} \mathrm{Yb}_{0.7} \mathrm{PO}_{4}$ materials implanted with three different doses of $\mathrm{Au}^{-}$ions $\left(1 \times 10^{14}, 5 \times 10^{14}\right.$, and $1 \times 10^{15}$ ions $\left./ \mathrm{cm}^{2}\right)$ are shown. Bulk powder XRD patterns from the as-synthesized materials are also shown. The dot symbol in (b) indicates the presence of an anomalous peak. The peak labelled with an asterisk symbol in (d) arises from both the monazite phase $\left[\left(\begin{array}{lll}0 & 1 & -2\end{array}\right)\right.$ peak $]$ and unreacted $\mathrm{Yb}_{2} \mathrm{O}_{3}\left[\begin{array}{lll}2 & 2 & 2\end{array}\right)$ peak]. Diffraction peaks from the impurity phase, $\mathrm{Yb}_{2} \mathrm{O}_{3}\left[\begin{array}{ll}2 & 2\end{array}\right)$ peak], observed in the pattern from $\mathrm{YbPO}_{4}$ and $\mathrm{La}_{0.3} \mathrm{Yb}_{0.7} \mathrm{PO}_{4}$ are represented by a diamond symbol.

Figure 4: Normalized P K-edge GA-XANES spectra from $\mathrm{LaPO}_{4}$ implanted with a dose of (a) $1 \times 10^{14}$ ions $/ \mathrm{cm}^{2}$ and (b) $1 \times 10^{15}$ ions $/ \mathrm{cm}^{2}$ are shown. The glancing angle and resulting X-ray attenuation depths are labelled in each plot. The spectrum from the as-synthesized material is also presented for comparison [33]. (For interpretation of the references to the colour in the figure legend, the reader is referred to the web version of this article.)

Figure 5: Normalized P K-edge GA-XANES spectra from $\mathrm{YbPO}_{4}$ implanted with a dose of (a) $1 \times 10^{14}$, (b) $5 \times 10^{14}$, and (c) $1 \times 10^{15}$ ions $/ \mathrm{cm}^{2} \mathrm{Au}^{-}$ions are shown. The glancing angle and resulting 
$\mathrm{X}$-ray attenuation depths are labelled in each plot. The spectrum from the as-synthesized material is also presented for comparison [33]. The arrow in Figure 5 (c) indicates the development of fine structure in the spectrum from $\mathrm{YbPO}_{4}$ that was implanted to the highest dose $\left(1 \times 10^{15}\right.$ ions $/ \mathrm{cm}^{2}$ ). (For interpretation of the references to the colour in the figure legend, the reader is referred to the web version of this article.)

Figure 6: Normalized $\mathrm{P}$ K-edge GA-XANES spectra from $\mathrm{La}_{0.7} \mathrm{Yb}_{0.3} \mathrm{PO}_{4}$ implanted with $\mathrm{Au}^{-}$ ions to a dose of (a) $1 \times 10^{14}$, (b) $5 \times 10^{14}$, and (c) $1 \times 10^{15}$ ions $/ \mathrm{cm}^{2}$ are shown. The glancing angle and resulting X-ray attenuation depths are labelled in each plot. The spectrum from the assynthesized material is also presented for comparison [33]. (For interpretation of the references to the colour in the figure legend, the reader is referred to the web version of this article.)

Figure 7: Normalized P K-edge GA-XANES spectra from $\mathrm{La}_{0.3} \mathrm{Yb}_{0.7} \mathrm{PO}_{4}$ implanted with $\mathrm{Au}^{-}$ ions to a dose of (a) $1 \times 10^{14}$, (b) $5 \times 10^{14}$, and (c) $1 \times 10^{15}$ ions $/ \mathrm{cm}^{2}$ are shown. The glancing angle and resulting X-ray attenuation depths are labelled in each plot. The spectrum from the assynthesized material is also presented for comparison [33]. The arrow in Figure 7 (c) indicates the development of fine structure after $\mathrm{La}_{0.3} \mathrm{Yb}_{0.7} \mathrm{PO}_{4}$ was implanted to the highest dose $\left(1 \times 10^{15}\right.$ ions $/ \mathrm{cm}^{2}$ ). (For interpretation of the references to the colour in the figure legend, the reader is referred to the web version of this article.)

Figure 8: Normalized P K-edge GA-XANES spectra from ion-implanted (a) $\mathrm{LaPO}_{4}\left(1 \times 10^{15}\right.$ ions $\left./ \mathrm{cm}^{2}\right)$, (b) $\mathrm{YbPO}_{4}\left(1 \times 10^{14}\right.$ ions $\left./ \mathrm{cm}^{2}\right)$, (c) $\mathrm{La}_{0.7} \mathrm{Yb}_{0.3} \mathrm{PO}_{4}\left(5 \times 10^{14}\right.$ ions $\left./ \mathrm{cm}^{2}\right)$, and (d) $\mathrm{La}_{0.3} \mathrm{Yb}_{0.7} \mathrm{PO}_{4}\left(5 \times 10^{14}\right.$ ions $\left./ \mathrm{cm}^{2}\right)$ annealed at $300^{\circ}$ and $900^{\circ} \mathrm{C}$ are shown along with the spectra from the as-synthesized and ion-implanted $\mathrm{La}_{1-\mathrm{x}} \mathrm{Yb}_{\mathrm{x}} \mathrm{PO}_{4}$ materials before annealing [33]. Only 
the spectra collected from a depth of $250 \mathrm{~nm}$ are shown. (For interpretation of the references to the colour in the figure legend, the reader is referred to the web version of this article.)

Figure 9: Normalized $\mathrm{PL}_{2,3}$-edge XANES spectra from ion-implanted (a) $\mathrm{LaPO}_{4}$, (b) $\mathrm{YbPO}_{4}$, (c) $\mathrm{La}_{0.7} \mathrm{Yb}_{0.3} \mathrm{PO}_{4}$, and (d) $\mathrm{La}_{0.3} \mathrm{Yb}_{0.7} \mathrm{PO}_{4}$ materials are shown along with the spectra from the assynthesized materials [33]. (For interpretation of the references to the colour in the figure legend, the reader is referred to the web version of this article.)

Figure 10: Normalized $\mathrm{PL}_{2,3}$-edge XANES spectra from ion-implanted (a) $\mathrm{La}_{0.7} \mathrm{Yb}_{0.3} \mathrm{PO}_{4}$ and (b) $\mathrm{La}_{0.3} \mathrm{Yb}_{0.7} \mathrm{PO}_{4}$ compounds annealed at $300^{\circ}$ or $900^{\circ} \mathrm{C}$ are presented along with the spectra from the as-synthesized materials and ion-implanted materials before annealing [33]. (For interpretation of the references to the colour in the figure legend, the reader is referred to the web version of this article.)

Figure 11: Normalized $\mathrm{La} \mathrm{L}_{3}$-edge GA-XANES spectra from ion-implanted $\mathrm{La}_{1-\mathrm{x}} \mathrm{Yb}_{\mathrm{x}} \mathrm{PO}_{4}(\mathrm{x}=$ 0.3 and 0.7 ) materials are shown along with the spectra from as-synthesized materials. (For interpretation of the references to the colour in the figure legend, the reader is referred to the web version of this article.) 
Figure 1

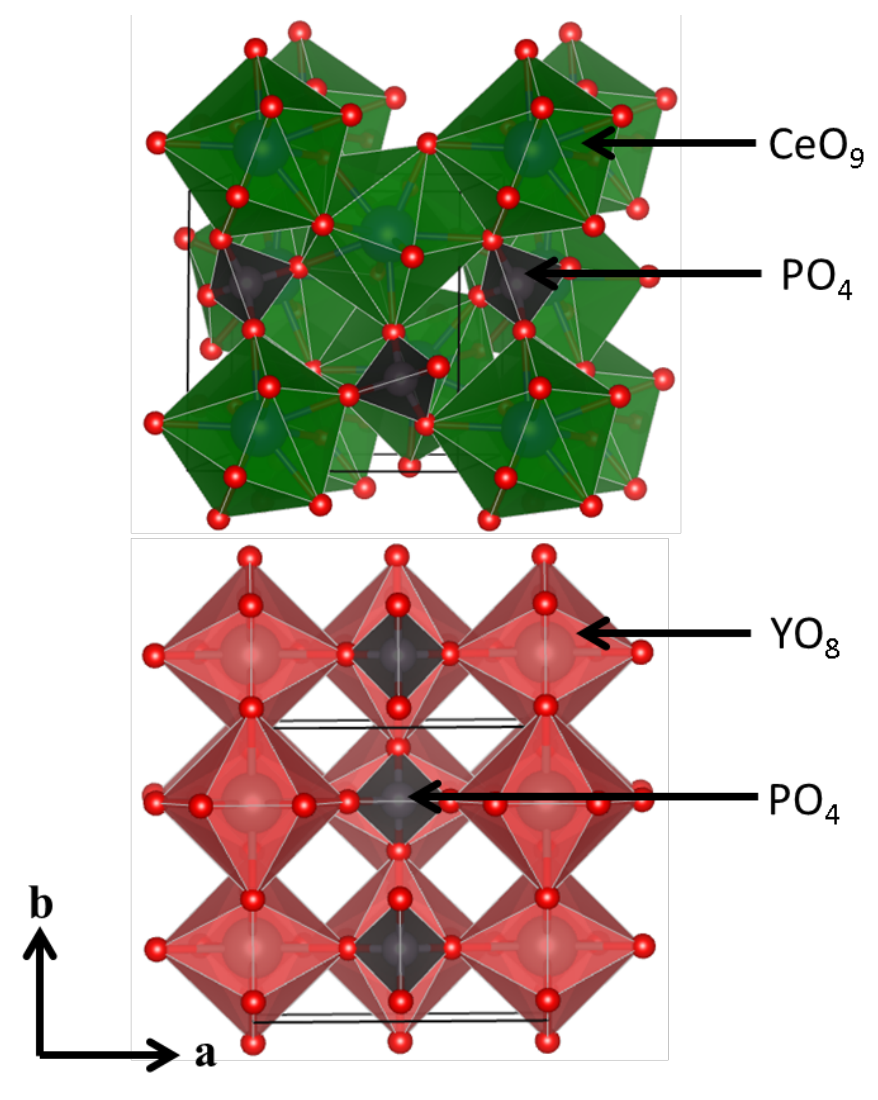


Figure 2

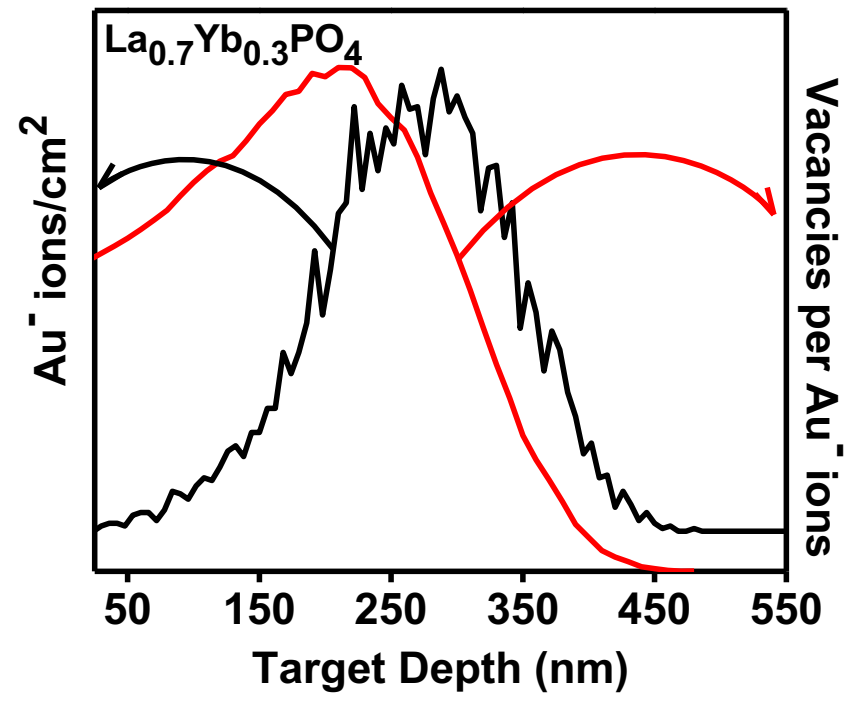


Figure 3
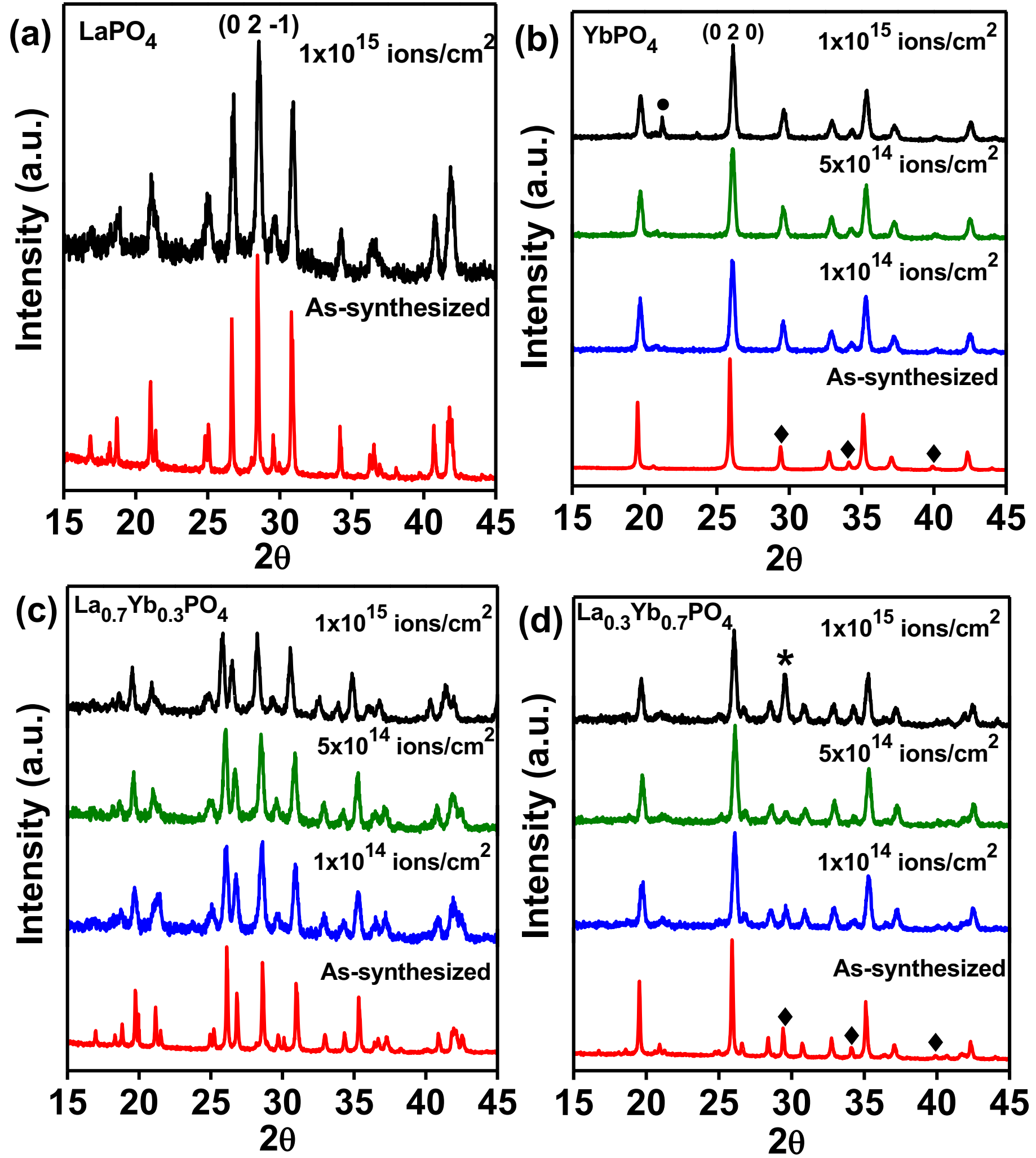
Figure 4
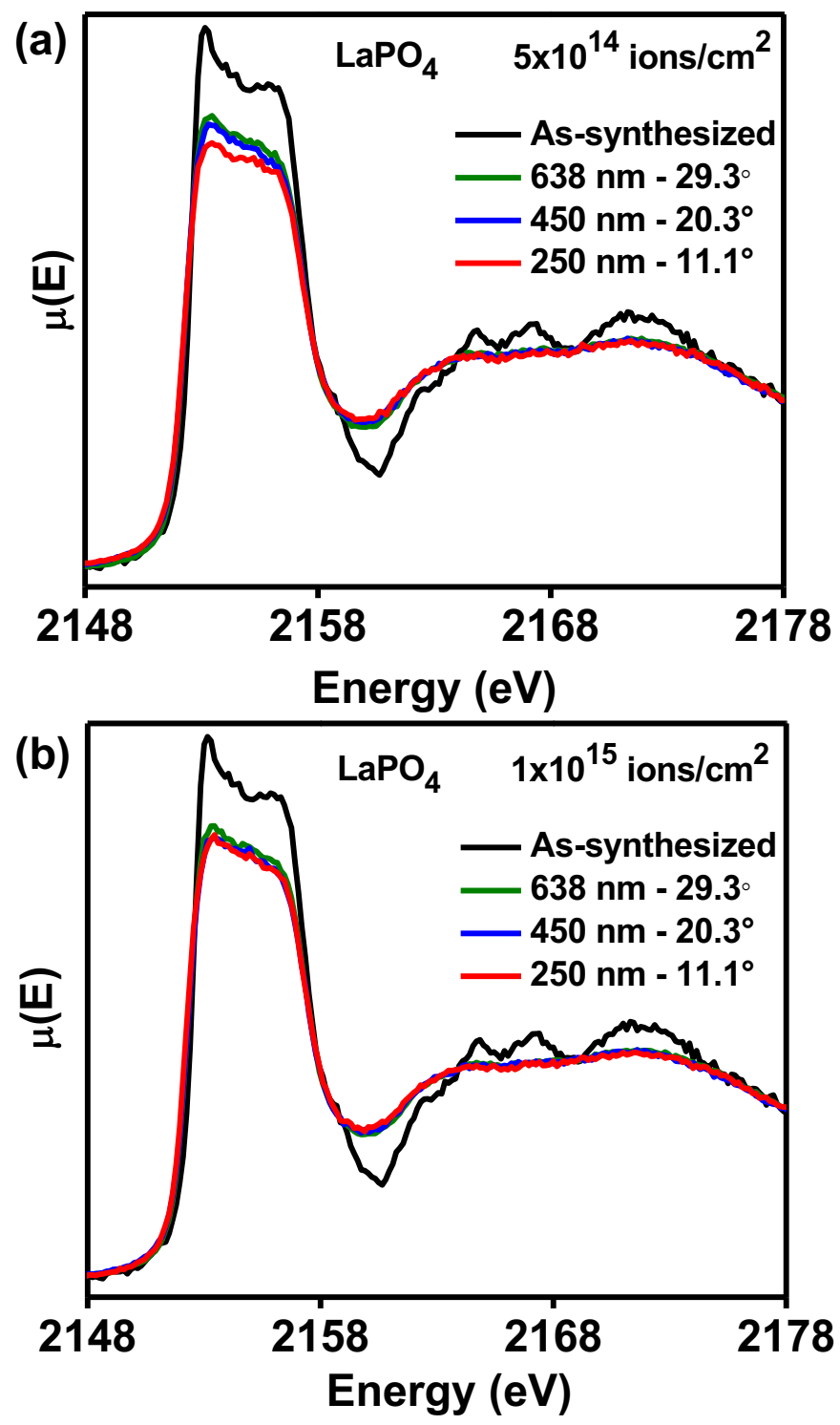
Figure 5
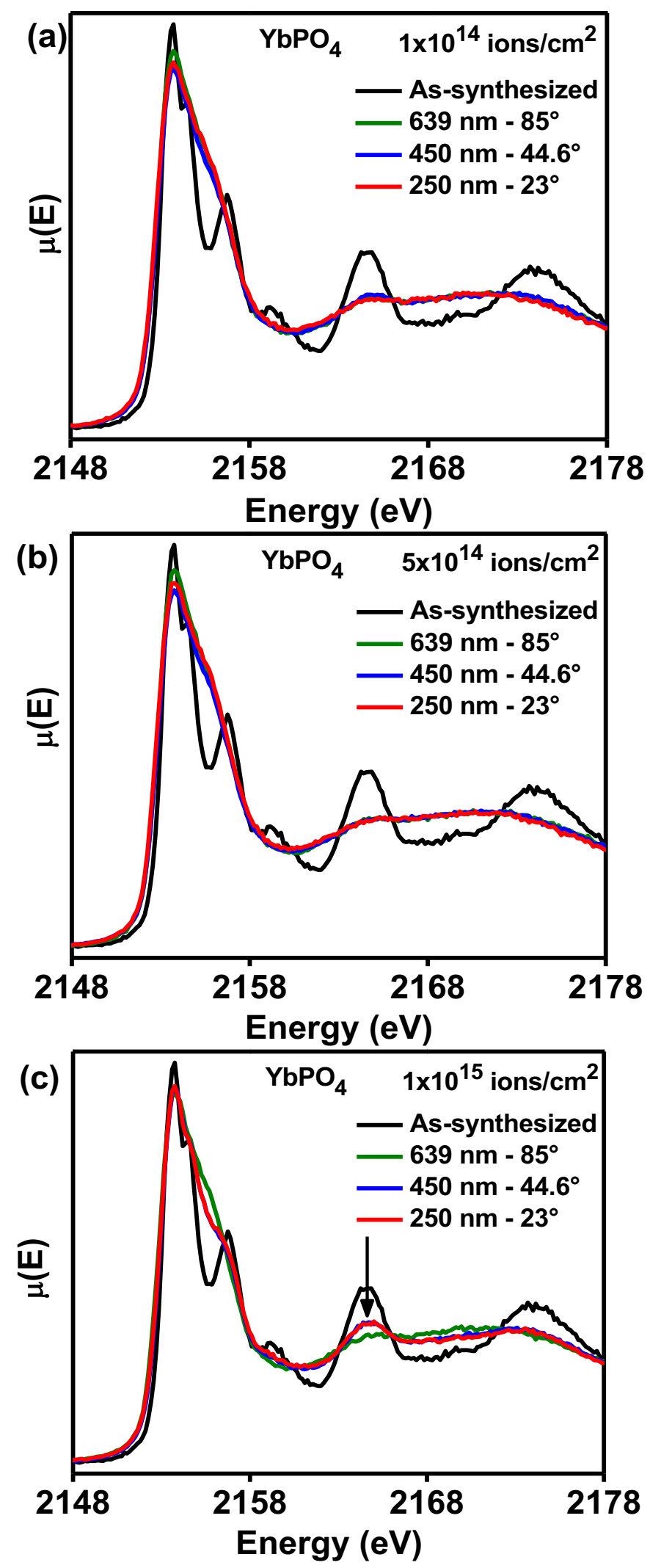
Figure 6
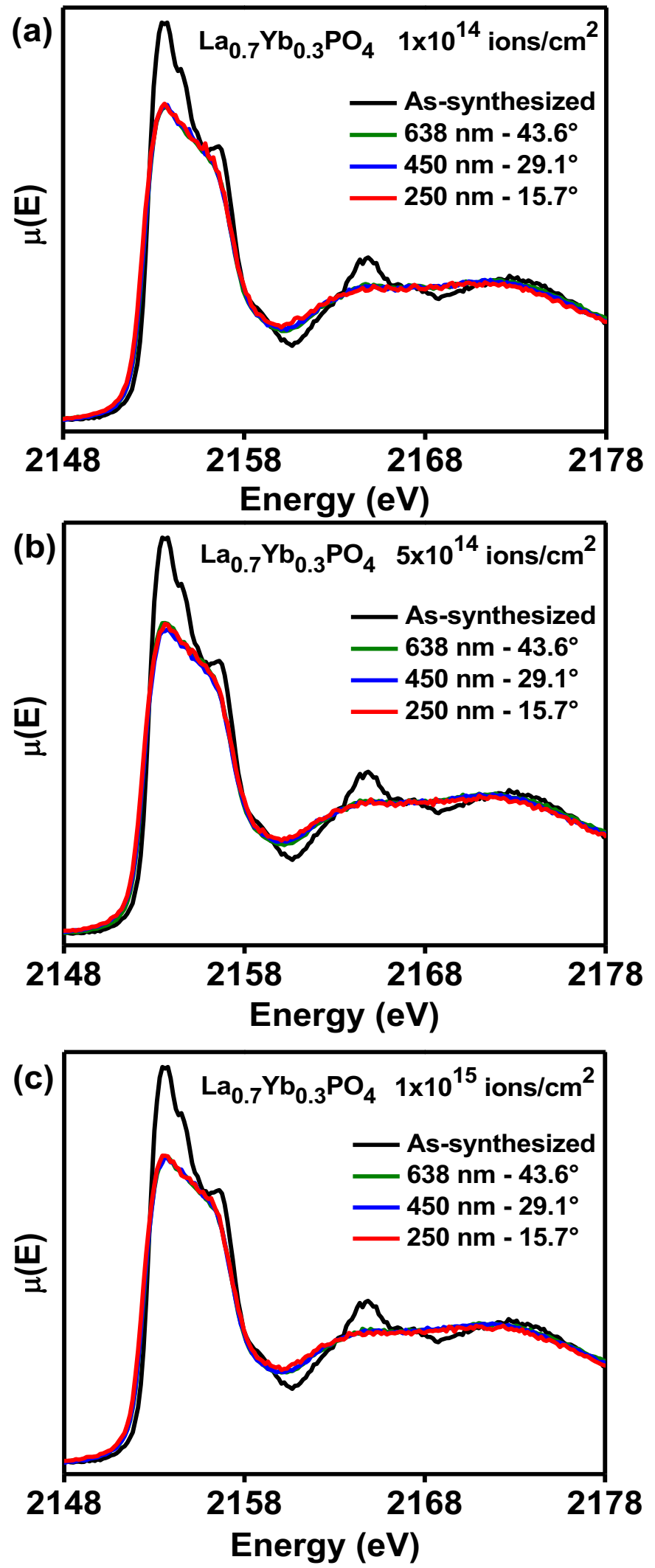
Figure 7
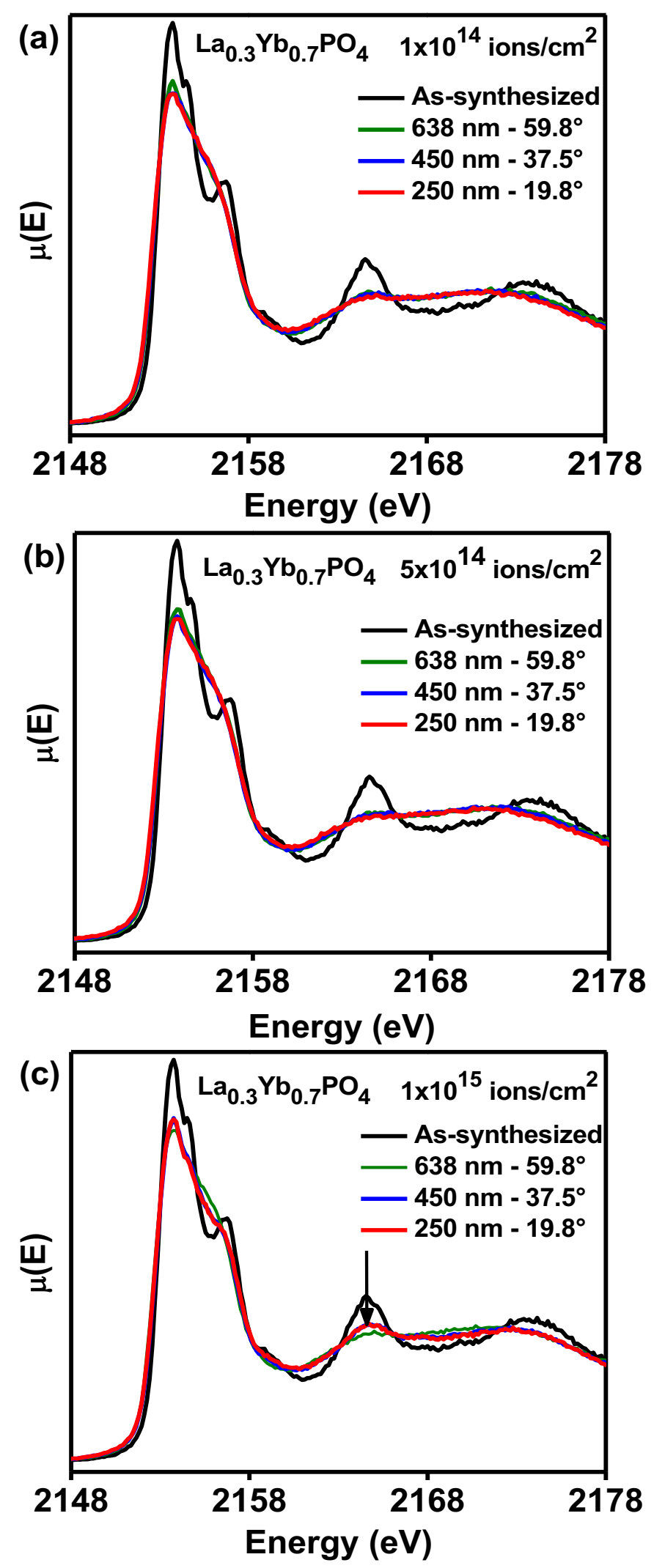
Figure 8
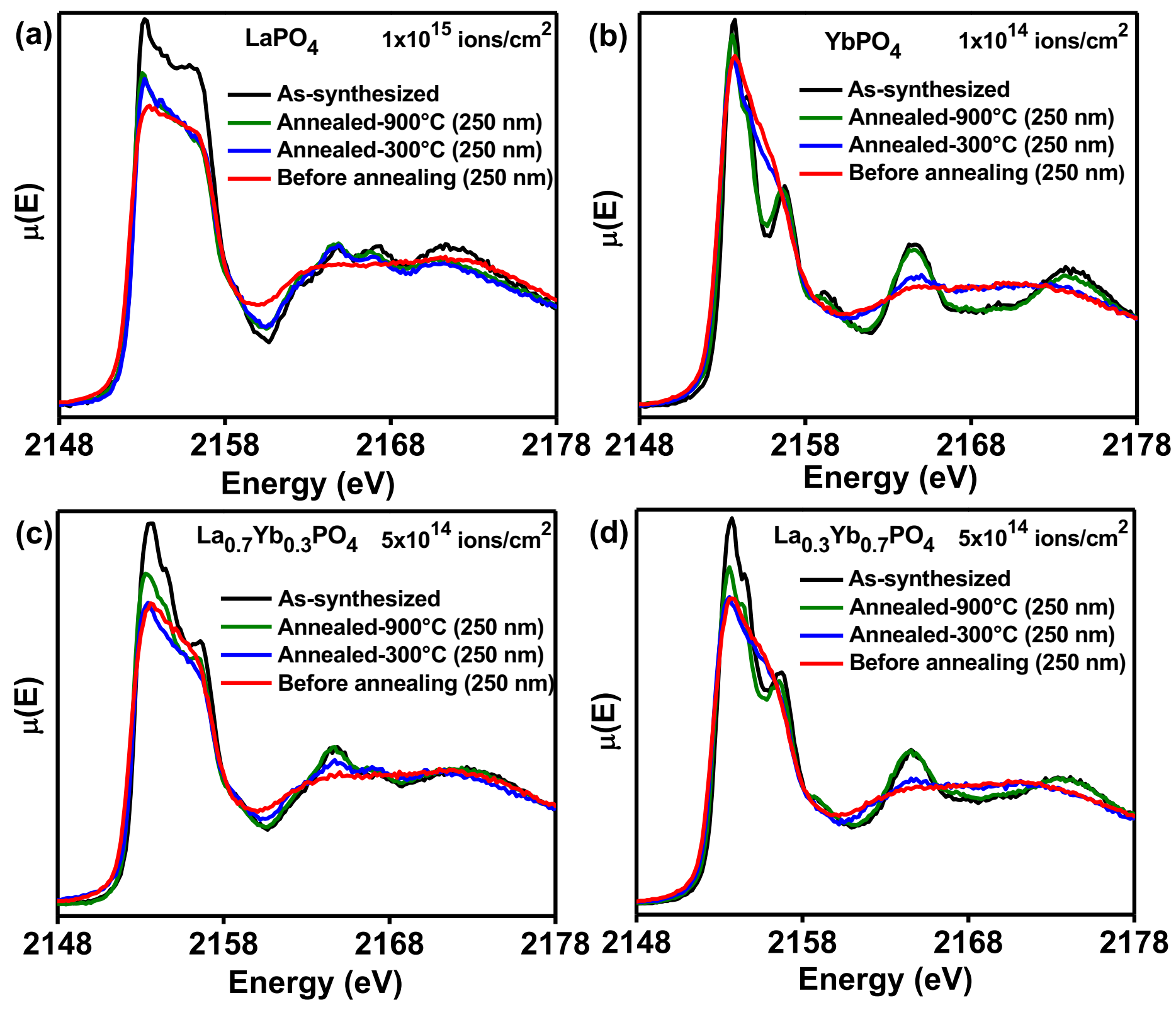
Figure 9
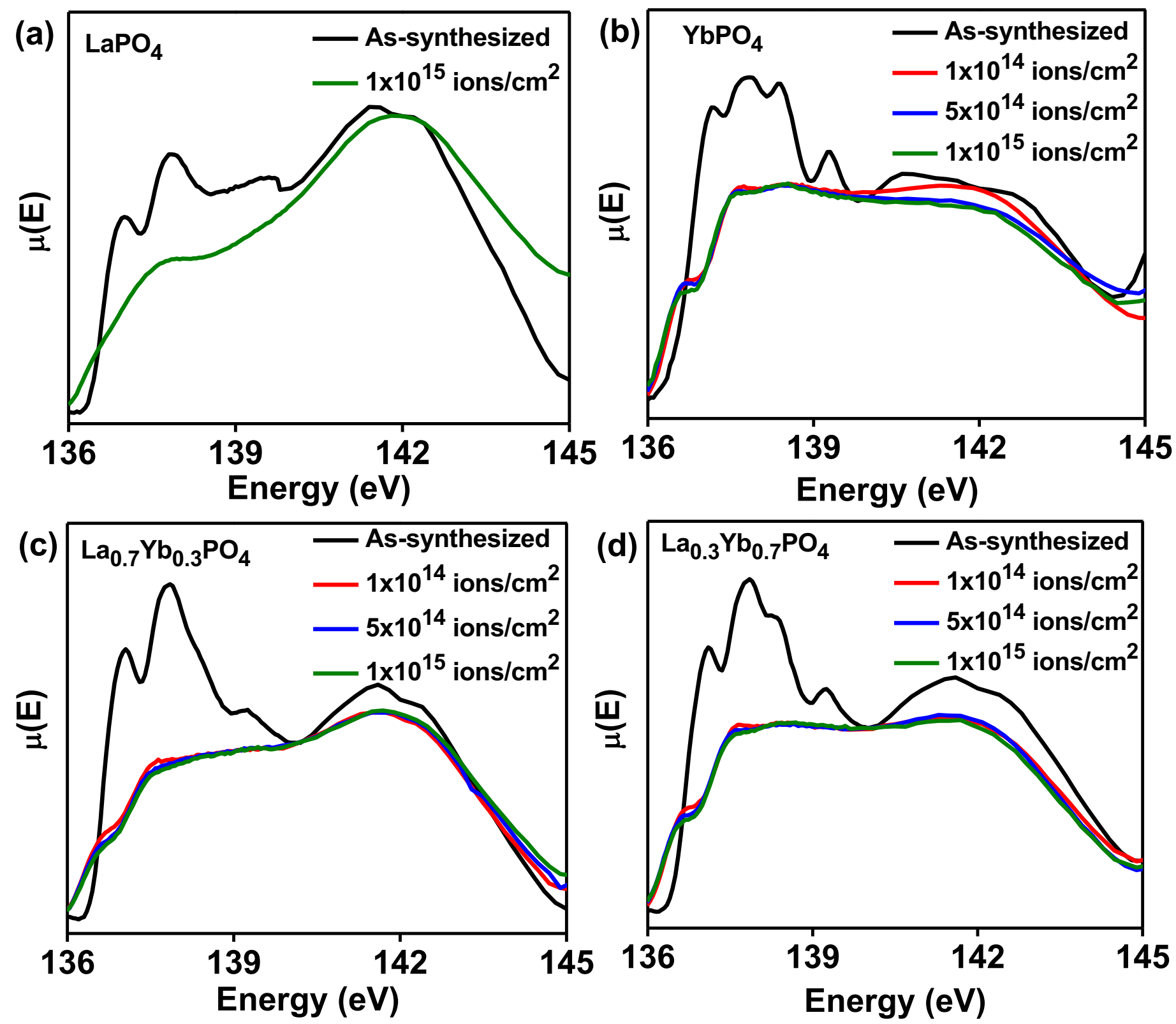
Figure 10
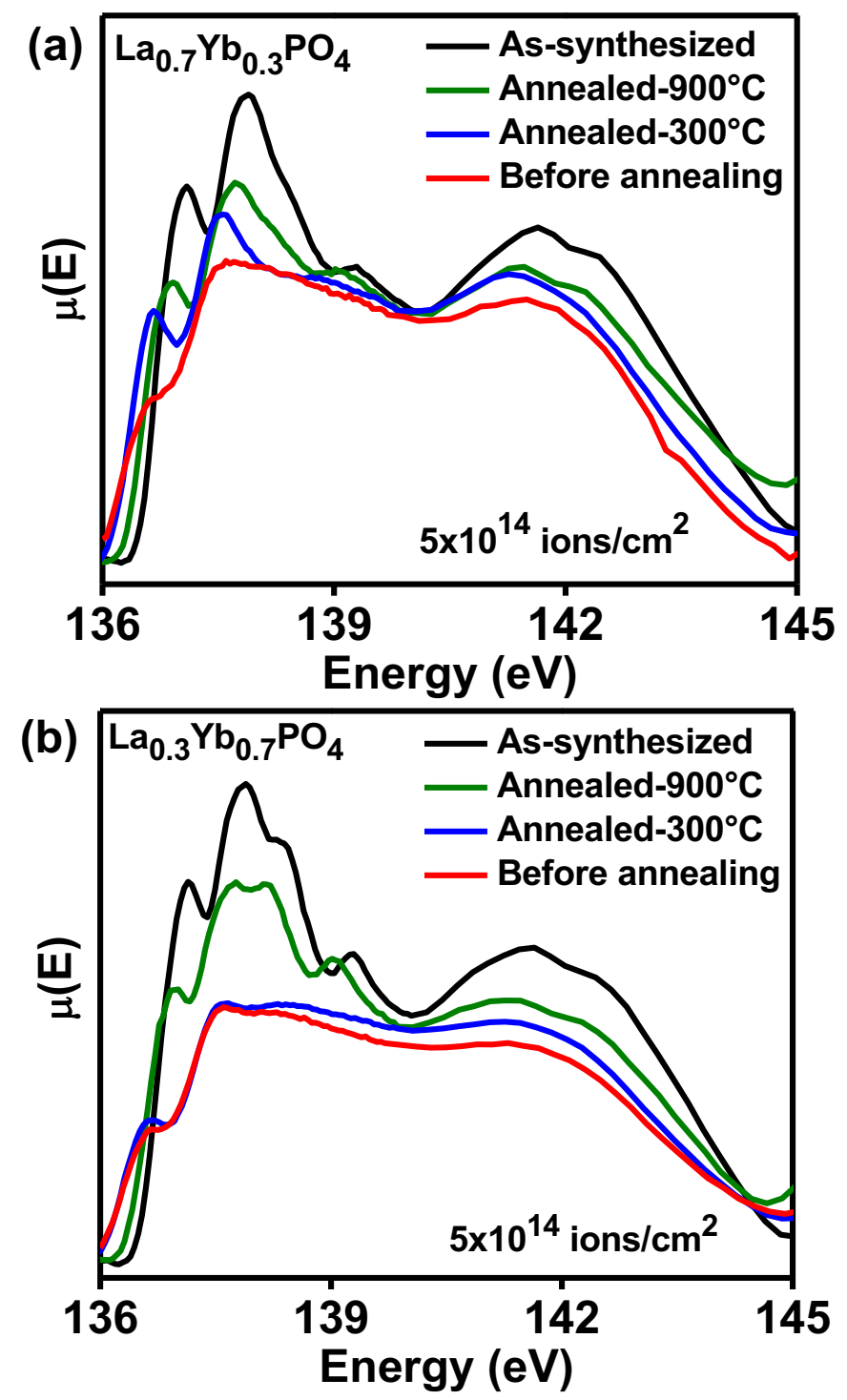
Figure 11
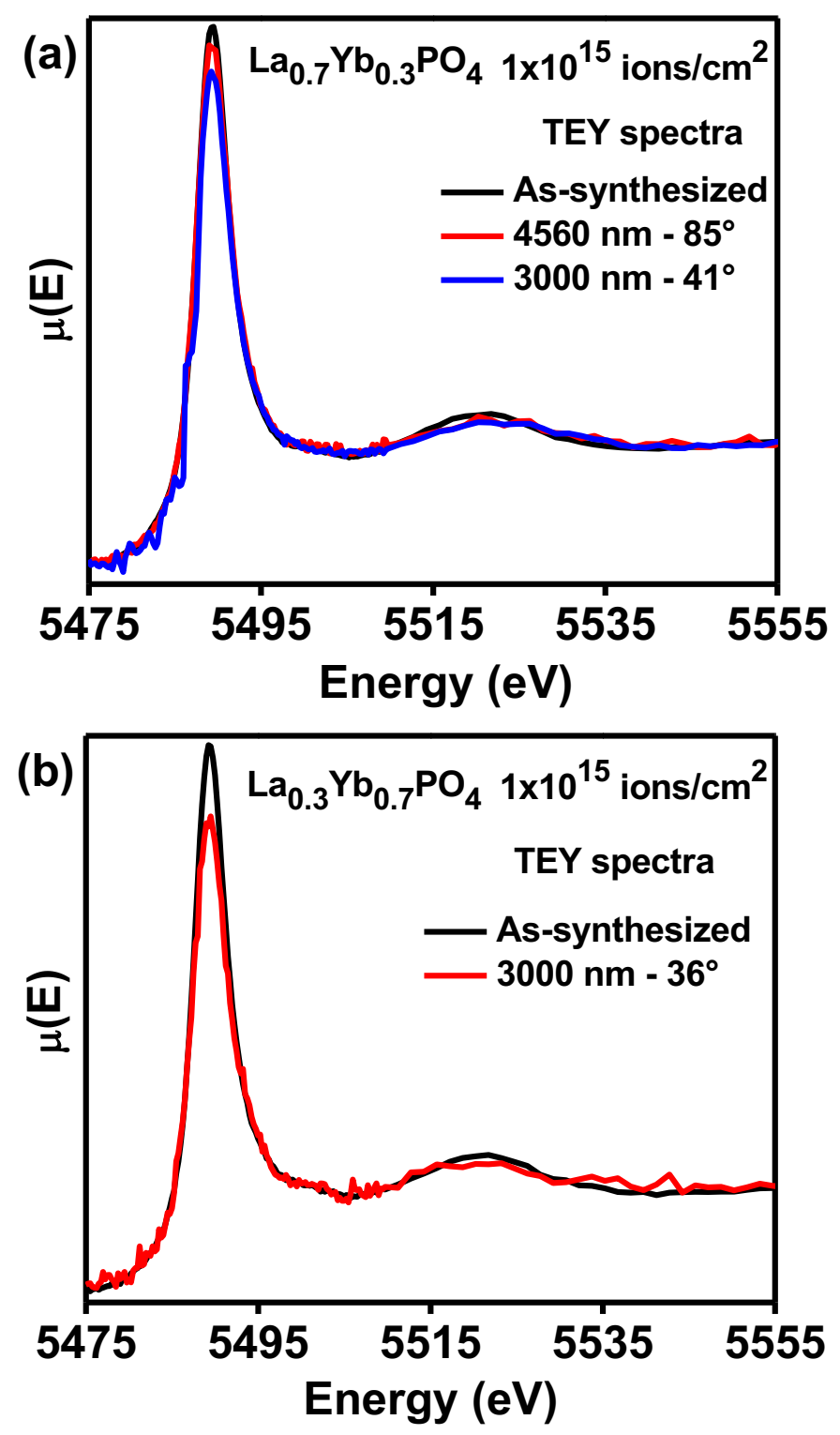